\title{
تصور مقترح لتنشيط السياحة الرياضية والعلاجية بمدينة سفاجا
}

\section{بمحافظة البحر الاحمر}

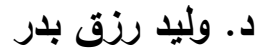

مدرس بقسم الإدارة الرياضية والترويح

كلية التربية الرياضية- جامعة أسوان

\section{نسرين قرشي شلتوت خليفة}

معلم تربية رياضية بإدارة شلاتين التعليمية
أ.د. عادل محمد عبد المنعم مكي

أستاذ الإدارة الرباضية وعميد كلية التربية

$$
\text { الرياضية }
$$

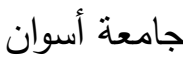

د. دممد حامد فتحي

مدرس بقسم الإدارة الرياضية والترويح

كلية التربية الرياضية - جامعة أسوان

مقدمة ومشكلة البحث :

تعتبر السياحة ظاهره إنسانية قديمة قدم المجتمعات الإنسانية، وقد تطورت

خلد النصف الثاني من القرن الواحد والعشرين تطورا كبيرا، أصبحت معه ظاهره عالمية، لا يستطيع احد إنكارها، حيث أثبتت أنها ظاهره ذات أثنار اقتصادية، واجتماعية، وثقافية وسياسية وبيئية بعيدة المدى، ولذا فقد تزايد الاهتمام العالمي بها، بوصفها أكبر الصناعات المولدة للدخل وفرص العمل، وقاطرة للتتمية الاقتصـادية، لما لها من تأثثر على مختلف القطاعات الاقتصادية. (س (1) . 9) فأصبح قطاع السياحة بمصر يمثل ركيزة أساسية للنشاط الاقتصادى، حيث

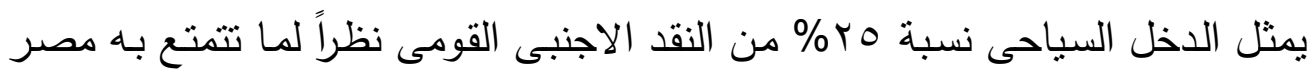

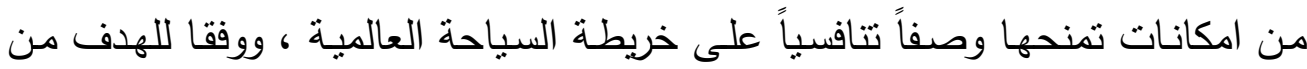
الرحلة التي يقوم بها السائح فيما بمثل أحد أبرز دوافع السفر بالنسبة لله فإن السياحة العلاجية والسياحة الرياضية يمثلان ركيزتين أساسيتين في ذلك. ويعد نمطا السياحة العلاجية والرياضية - من انماط السياحة التى تحتاج الى امكانات طبيعية تستتد إليها وتكون مبرراً لقيامها، وكذلك تحتاج إلى امكانات بشرية وخدمات سياحية نساعد على استخلال تلك الامكانات .(1) 
ومن أبرز الامكانات الطبيعية للسياحة العلاجية والرياضية فى مصر : الموقع الجغرافى، العيون المعدنية والكبريتية، الرمال المشعة، الطين العلاجى، ومظاهر السطح كالمناطق الجبلية التى تشفى من بعض الأمراض سواء المزمنة منها أو الحادة، وذلك

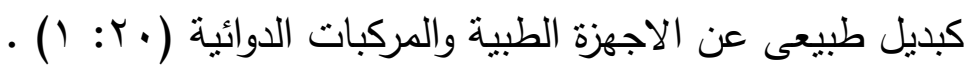
ومن بين الامكانات البشرية تسهيلات الإقامة العلاجية ووفرة الخبرة الطبية من أطباء وممرضين ورعاية الدولة والعمالة السياحية والخدمات والتسهيلات السياحية،

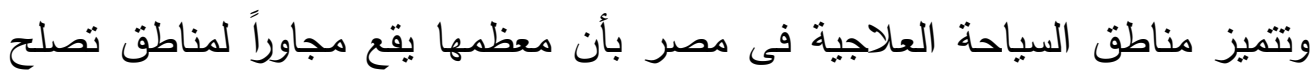
لممارسة أنماط أخرى من السياحة، ذلك مما بدعم نشاط السياحة العلاجية بها، حيث يمكن للسائح العلاجى أن يمارس أنواع أخرى من السياحة بعد الانتهاء من العلاج وخلال فترة النقاهة. وتعتمد السياحة العلاجية على تكامل الامكانات طبيعية الموجودة بالبيئة فيما بينها فى بيئة العرض السياحى مثل تكامل الموقع الجغرافى المتوسط لمقصد سياحى مع وفرة العيون المعدنية والكبريتية لجذب سائحى العلاج ويؤكد على لهى هذا التكامل ايضاً ان بعض طرق وقه العلاج البيئى تجمع بين موردين طبيعيين لعلاج مرض معين كما هو الحال فى استخدام اشعة الثمس مع مياه البحر فى علاج بعض الثى

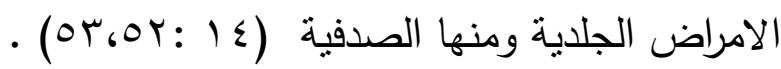
ومن جهة أخرى تعد السياحة الرياضية أحد دعامـات الصناعة الحديثة التي يجب أن توليها مصـر الاهنمـام الكافي حتى نسـنطيع ان تجلب ثمارهـا ،كمـا تعنبر السياحة الرياضية من أهم أنواع السياحة التي تساهم بشكل فعال فى تتشيط حركة

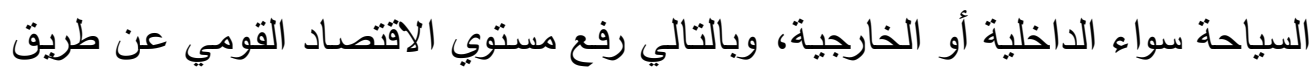

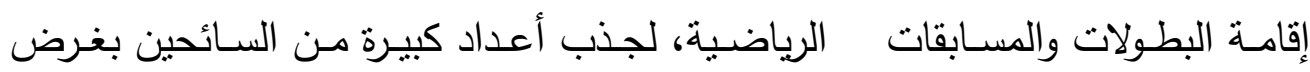
المشاركة السلبية أو الايجابية فى هذه المناسبات أو البطولات الرياضية. (10 : اب؟)

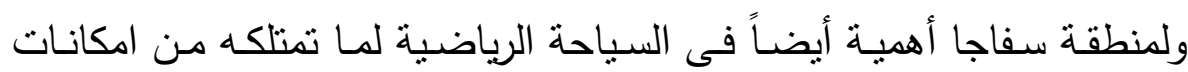

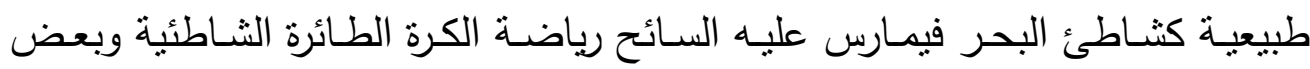
الألعاب الجماعية والألعاب الصغيرة ورياضة المشى والتمرينات البدنية، والبحر يمارس 
فيه الكثير من الرياضـات المائية مثل الغطس والغوص والتجديف والثـراع والسباحة والدراجات المائية وصيد الاسماك، بالإضافة الى الإمكانات الهائلة الموجودة فى القرى

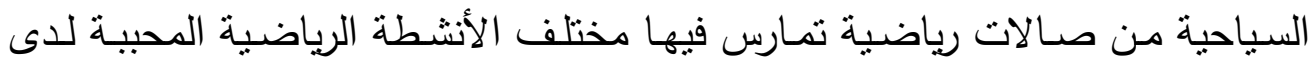

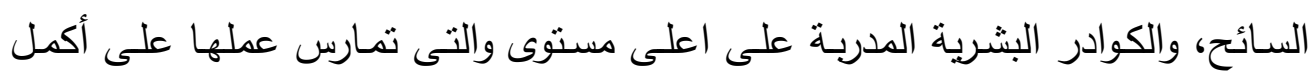
وجـه لتحقيـق النهوض والتتميـة فى السياحة عامـة والسـياحة الرياضـية خاصـة (1)

ولقد حاولت بعض الدراسات القليلة تتمية وتطوير بعض أنواع السياحة بمصر ،

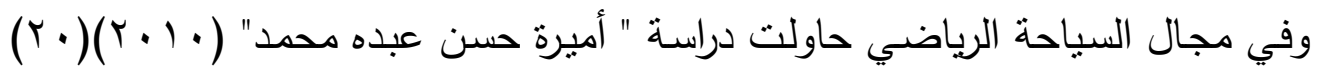
وعنوانها "دور الاحداث الرياضية في تتمية الحركة السياحية الوافدة الي مصر ومن حيث السياحة العلاجية.

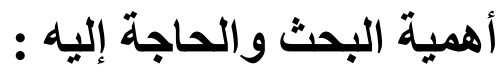
قد يمثل هذا البحث طفرة جديدة فى مجال البحوث ذات العلاقة الارتباطية بين السياحة والرياضة ويؤدى إلى التعرف على نقاط القوة والضعف بمنطقة متميزة سياحياً بمصر هي مدينة سفاجا بمحافظة البحر الأحمر من خلال دراسة امكانات السياحة العلاجية والرياضية وسبل فعاليتها وتتشيطها. هدف البحث: :

$$
\text { يهذف هذا البحث إلى وضع : }
$$

" نموذج مقترح لتفعيل امكانات السياحة الرياضية والعلاجية بمدينة سفاجا بمحافظة البحر الأحمر" وذللك من خلال الإجابة علي التساؤلات التالية : 1 - ما امكانات السياحة الرياضية بمدينة سفاجا بمحافظة البحر الأحمر ؟.

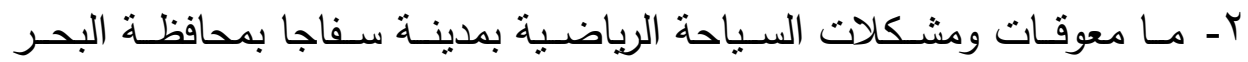

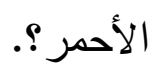

ب- الامكانات المادية والبشرية في مجال السياحة الرياضية ؟. ع - ما التحديات المعاصرة التى نؤثر على السياحة الرياضية محلياً وعالمياً؟ 


\section{- \\ استخدم الباحثون المنهج الوصفي.

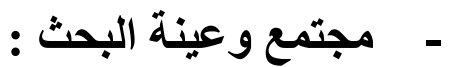

- - يتمنل مجتمع البحث في المسؤلين في القري السياحية بمدينة سفاجا بمحافظة

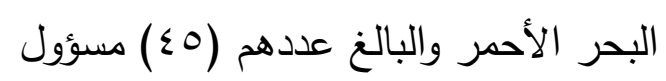

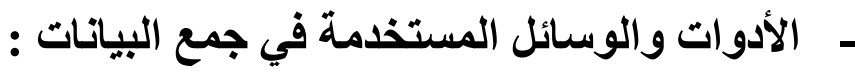

استخدم الباحثون الأدوات والوسائل التالية : المئية

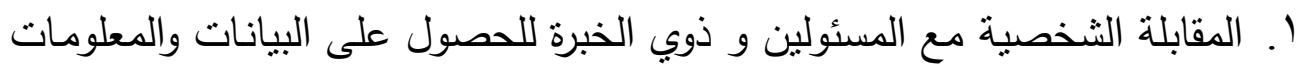

$$
\text { التي تفيد الدراسة . }
$$

r. الاستبيان : وهو من تصميم الباحثون .

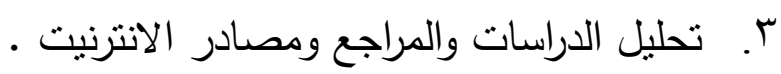

المعاملات العلمية لاستبيان السياحة الرياضية:

صدق استبيان السياحة الرياضية:

صدق الاتساق الاخلى لاستبيان السياحة الرياضية:

تم التحقق من صدق الاستبيان بإستخدام لاتساق الداخلى لمحاور الاستبيان وعباراته

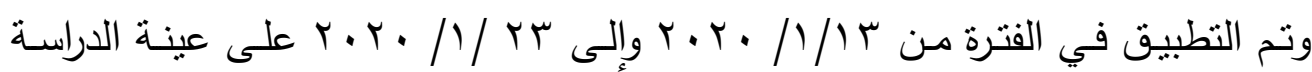
الاستطلاعية وقوامها (· (r) فرداً من العاملين بوزارة السياحة والأخصائيين الرياضيين بوزارة الثباب والرياضـة واعضـاء هيئة التدريس فى مجالى الادارة الرياضية والسباحة وقد قام الباحثُن بالخطوات الأثية : حساب معامل الارتباط بين درجة كل عبارة والدرجة الكلية للمحور ، وحساب معاملات الارتباط بين مجموع درجات كل محور والدرجة الكلية للاستبيان. 


\section{جدول (1)}

النسبة المئوية لمو افقة الخبر اء على مفردات الاستبيان فى المحور الخاص بإسهامات

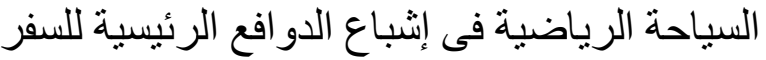

\begin{tabular}{|c|c|c|c|}
\hline النسبة المئوية للموافقة & لاأوافق & أوافق & الدافع \\
\hline$\% 1 \ldots$ & - & 11 & التمتع بالممارسة في أحضان الطبيعة \\
\hline$\% \wedge 1 . \wedge r$ & r & 9 & مصاحبة الأسرة . \\
\hline$\% 9 \cdot .91$ & 1 & $1 \cdot$ & الراحة والاستجمام . \\
\hline$\% \wedge 1 . \wedge r$ & $r$ & 9 & التدريب على نشاط رياضي معين . \\
\hline$\% 1 \ldots$ & - & 11 & مر افقة الزملاء ـ \\
\hline$\% \wedge 1 . \wedge r$ & r & $q$ & الإنجــــــــز . \\
\hline$\% \wedge 1 . \wedge r$ & Y & 9 & دو افع مهنية \\
\hline$\% 9 \cdot .91$ & 1 & $1 \cdot$ & دوافع ثقافية . \\
\hline$\% 1 \ldots$ & - & 11 & الحاجة إلى الهروب من ضغوط الحياة \\
\hline$\% \wedge 1 . \wedge r$ & Y & 9 & اكتشاف النفس . \\
\hline$\% \wedge 1 . \wedge r$ & Y & 9 & المخاطــرة . \\
\hline$\% \wedge 1 . \wedge r$ & Y & 9 & التحدي . \\
\hline$\% \wedge 1 . \wedge r$ & r & 9 & البحث عن كل مـا هو جديد . \\
\hline$\% 1 \ldots$ & - & 11 & التسلية والترفيه . \\
\hline$\% 9 \cdot .91$ & 1 & $1 \cdot$ & ارتياد أماكن جديدة . \\
\hline$\% 1 \ldots$ & - & 11 & التحديد . \\
\hline$\% \wedge 1 . \wedge r$ & r & 9 & 1 \\
\hline
\end{tabular}


* يتضـح مـن جدول ( (1) ان : نسبة مو افقة السـادة الخبر اءعلى مفردات الاستبيان فىى المحور الخاص بإسهامات السياحة الرياضية فى إثباع الدو افع الرئيسية للسفر تتر اوح

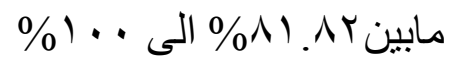

جدول (r)

النسبة المئوية لموافقة الخبراء على مفردات الاستبيان فى المحور

الخاص

\begin{tabular}{|c|c|c|c|c|}
\hline للموافقة المئوية & لأوافق & أوافق & الرياضة & 5 \\
\hline$\%$ & - & 11 & المشى . & 1 \\
\hline$\% 1 \ldots$ & . & 11 & الجرى . & r \\
\hline$\% 9 \cdot .91$ & 1 & 1. & الفروسية & $\mu$ \\
\hline$\% 1 \ldots$ & $\cdot$ & 11 & كرة الماء & $\varepsilon$ \\
\hline$\% 1 \ldots$ & . & 11 & الدر اجات المائية . & 0 \\
\hline$\% 1 \ldots$ & . & 11 & سباقات السيار ات & 7 \\
\hline$\% \wedge \Lambda . \wedge r$ & $r$ & 9 & تنس الطاولة . & $\mathrm{V}$ \\
\hline$\% 9 \cdot .91$ & 1 & 1. & التنس الارضى . & $\Lambda$ \\
\hline$\% 1 \ldots$ & . & 11 & الجولف . & 9 \\
\hline$\% 9 \cdot .91$ & 1 & 1 . & البلياردو . & 1. \\
\hline$\% 9 \cdot .91$ & 1 & 1 . & ركوب الخيل . & 11 \\
\hline$\% 1 \ldots$ & $\cdot$ & 11 & ركوب الدراجات . & IT \\
\hline$\% \wedge \perp . \wedge r$ & $r$ & 9 & الهوكى . & $1 T$ \\
\hline$\% \wedge \perp . \wedge r$ & r & 9 & كرة القدم . & $1 \varepsilon$ \\
\hline$\% \wedge \perp . \wedge r$ & $r$ & 9 & كرة السلة & 10 \\
\hline$\% \wedge 1 . \wedge r$ & $r$ & 9 & الكرة الطائرة & 17 \\
\hline$\% \wedge \perp . \wedge r$ & $r$ & 9 & كرة اليد . & IV \\
\hline$\% 1 \ldots$ & $\cdot$ & 11 & الاسكو اش . & 11 \\
\hline$\% 9 \cdot .91$ & 1 & 1. & رمى السهام . & 19 \\
\hline
\end{tabular}




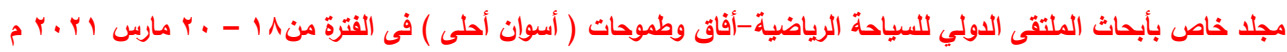
(العدد الثالث)

\begin{tabular}{|c|c|c|c|c|}
\hline$\% 1 \ldots$ & $\cdot$ & 11 & ارتياد الصحر اء . & $r$. \\
\hline$\% 1 \ldots$ & $\cdot$ & 11 & تسلق الجبال . & YI \\
\hline$\% 1 \ldots$ & - & 11 & الاستجمام على اطئ . الثئ & Tr \\
\hline$\% 1 \ldots$ & - & 11 & النز هات البحرية . & $r$ \\
\hline$\% 1 \ldots$ & $\cdot$ & 11 & التصوير تحت الماء . & $r \varepsilon$ \\
\hline$\% 1 \ldots$ & . & 11 & التجديف . & ro \\
\hline $0 / 01 \ldots$ & - & 11 & القو ارب . & $r 7$ \\
\hline 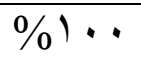 & - & 11 & صيد الأسماك بالقوارب & TV \\
\hline
\end{tabular}

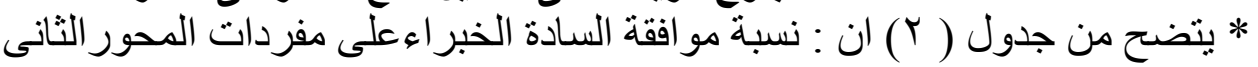

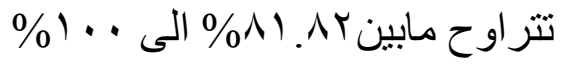




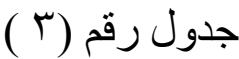

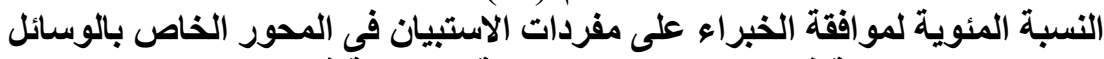

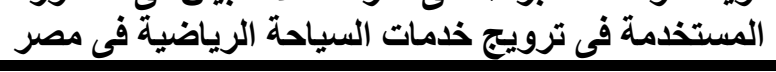

\begin{tabular}{|c|c|c|c|c|}
\hline النسبة المئوية \% & 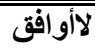 & أوافق & وسيلــة الترويـــج & $\bar{p}$ \\
\hline$\% \wedge \Lambda . \wedge r$ & $\bar{r}$ & 9 & المحطات التليفزيونية المحلية . & 1 \\
\hline$\% 1 \ldots$ & - & 11 & المحطات التليفزيونية الفضائية . & $r$ \\
\hline$\% \wedge \Lambda . \wedge r$ & $r$ & 9 & المحطات الإذاعية المحلية . & $r$ \\
\hline$\% 1 \ldots$ & . & 11 & المحطات الإذاعية الدولية . & $\varepsilon$ \\
\hline$\% 9 \cdot .91$ & 1 & 1. & الثبكة العالمية للمعلومات ( الإنترنت ) . & 0 \\
\hline$\% 9 \cdot .91$ & 1 & 1. & الجرائد اليومية المحلية . & 7 \\
\hline$\% 1 \ldots$ & . & 11 & الجرائد اليومية الدولية . & $\mathrm{v}$ \\
\hline$\% \wedge \Lambda . \wedge r$ & r & 9 & الجرائد الأسبوعية المحلية . & $\Lambda$ \\
\hline$\% 9 \cdot .91$ & $T$ & 1. & الجرائد الأسبوعية الدولية. & 9 \\
\hline$\% 9 \cdot .91$ & 1 & 1. & الجرائد السياحية المحلية. & 1. \\
\hline$\% 1 \ldots$ & . & 11 & الجرائد السياحية الدولية . & 11 \\
\hline$\% 1 \ldots$ & . & 11 & المجلات المتخصصة في المجال السياحي . & Ir \\
\hline$\% 1 \ldots$ & . & 11 & المجلات الرياضية الربع سنوية . & 14 \\
\hline$\% 1 \ldots$ & . & 11 & المجلات الرياضية النصف سنوية . & $1 \leq$ \\
\hline$\% \wedge \Lambda . \wedge r$ & r & 9 & المجلات الرياضية السنويةة . & 10 \\
\hline$\% 9 \cdot .91$ & 1 & 1. & صفحات الإنترنت في الاتحادات الإقليمية . & 19 \\
\hline$\% 9 \cdot .91$ & 1 & 1. & صفحات الإنترنت في الاتحادات الدولية . & IV \\
\hline$\% 1 \ldots$ & . & 11 & الثركات السياحية المحلية . & 11 \\
\hline$\% 1 \ldots$ & . & 11 & الثركات السياحية الدولية . & 19 \\
\hline$\% 1 \ldots$ & . & 11 & منظمي الرحلات السياحيةة. & r. \\
\hline$\% \wedge 1 . \wedge r$ & $r$ & 9 & البورصات السياحية المحلية . & rI \\
\hline$\% \wedge \Lambda . \wedge r$ & r & 9 & البورصات السياحية الدولية . & YY \\
\hline$\% 9 \cdot .91$ & 1 & 1. & مطبو عات المؤتمرات السياحية في العالم . & Yr \\
\hline$\%$ & - & 11 & شركات الطيران الوطنية. . & Y $\varepsilon$ \\
\hline$\% 9 \cdot .91$ & 1 & 1. & شركات الطيران الأجنبيةة . & ro \\
\hline$\% 9 \cdot .91$ & 1 & 1. & الجهة الرياضية المنظمة للحدث . & Y \\
\hline$\% \wedge \wedge . \wedge r$ & r & 9 & وكالات الأبباء العربية الناطقة باللغة الأجنبية . & $T V$ \\
\hline
\end{tabular}




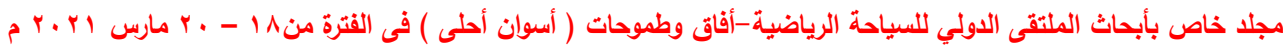

(العدد الثالث)

\begin{tabular}{|c|c|c|c|c|}
\hline$\% \wedge 1 . \wedge r$ & r & 9 & وكالات الأنباء الأجنبية . & $r \wedge$ \\
\hline$\% 9 \cdot .91$ & 1 & 1. & مجلات الاتحادات الرياضية الدولية . & $r q$ \\
\hline$\% \wedge 1 . \wedge r$ & $r$ & 9 & مجلات الأندية الرياضية المشهورة . & $r$. \\
\hline
\end{tabular}

يتضـح مـن جـول (ب) ان : نسـبة مو افقة السـادة الخبر اءعلى مفـردات المحور الثالـث.

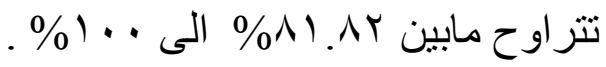

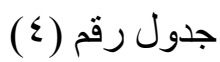

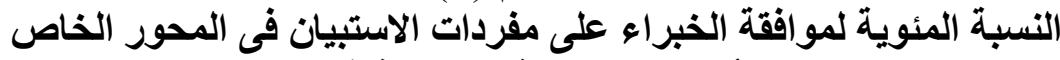

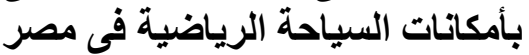

\begin{tabular}{|c|c|c|c|c|}
\hline اللموبة افقة المئوية & 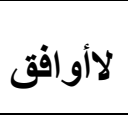 & أوافق & المبارة & r \\
\hline$\%$ & $\bar{r}$ & 9 & هل تتوافر القيادات الرياضية المؤهلة للعمل في مجال السياحة الرياضية ؟ & \\
\hline$\% \wedge 1 . \wedge r$ & $r$ & 9 & |لمشرفين الرياضيين التعامل مع مختلف ثقافات السائحين ؟ & $r$ \\
\hline$\% \wedge 1 . \wedge r$ & r & 9 & 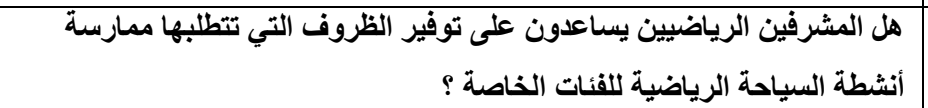 & $\boldsymbol{r}$ \\
\hline$\% \wedge 1 . \wedge r$ & $r$ & 9 & هل تتو افر الخبرة لدى العاملين بالعلاقات العامة في مجال السياحة الرياضية ؟ & $\varepsilon$ \\
\hline$\% \wedge 1 . \wedge r$ & r & 9 & هل يوجد برامج للتشيط والتسويق في مجال السياحة الرياضية ؟ & $\bullet$ \\
\hline$\% \wedge 1 . \wedge r$ & r & 9 & هل البرامج الرياضية يراعى فيها الرغبات المتنوعة للسائحين الممارسين ؟ & 7 \\
\hline$\% \wedge 1 . \wedge r$ & r & 9 & | الأنشطة الرياضية إنظآت الرياضية المتوفرة داخل القرى السياحية ممارسة جميع & $\checkmark$ \\
\hline$\% \wedge 1 . \wedge r$ & r & 9 & | لهل يتوافر عمال النظافة بصورة كافية في أماكن ممارسة الأنشطة الرياضية & $\Lambda$ \\
\hline$\% \wedge 1 . \wedge r$ & r & 9 & 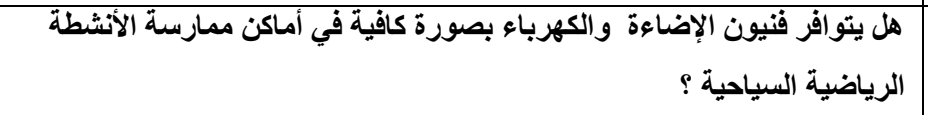 & 9 \\
\hline$\% \wedge 1 . \wedge r$ & r & 9 & 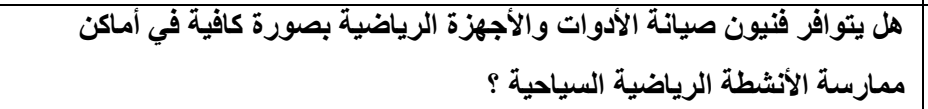 & $1 \cdot$ \\
\hline$\% \wedge 1 . \wedge r$ & r & 9 & هل البرامج الرياضية تتقق مع ميول واحتياجات وثقافات السائحين المختلفة ؟ & 11 \\
\hline$\% \wedge 1 . \wedge r$ & r & 9 & في مصر ؟ هلك تعريف كافي بالأماكن السياحية التي يمكن ممارسة الأتشطة الرياضية بها & Ir \\
\hline$\% \wedge 1 . \wedge r$ & r & 9 & | هل الأماكن الخاصة بالإعاشة أثناء الأقامات الرياضية مناسبة ؟ & Ir \\
\hline
\end{tabular}




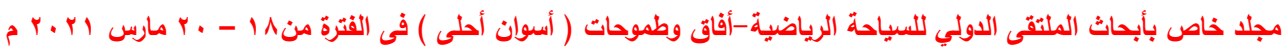

\begin{tabular}{|c|c|c|c|c|}
\hline$\% 9 \cdot .91$ & 1 & $1 \cdot$ & هل يمكن أستغلال الأماكن الطبيعية بثكل أفضل في خدمة السياحة الرياضية ؟ & $1 \varepsilon$ \\
\hline$\% \wedge 1 . \wedge r$ & r & 9 & لهل تلتوافر الأدوات والأجهزة الرياضية بصورة كافية في أماكن ممارسة الرياضات & 10 \\
\hline$\% \wedge 1 . \wedge r$ & r & 9 & كافية ؟ الإجراءات الجمركية تسهل من اصطحاب السائح للأجهزة الرياضية بصورة & 17 \\
\hline$\% \wedge 1 . \wedge r$ & r & 9 & هل تتو افز وسائل النقل البرى الخاصة بخدمة السياحة الرياضية بصورة كافية ؟ & 18 \\
\hline$\% \wedge 1 . \wedge r$ & r & 9 & هل تتوافر وسائل النقل البحري التي تتطلبها ممارسة بعض الرياضات السياحية ؟ & 11 \\
\hline$\% \wedge 1 . \wedge r$ & r & 9 & هل تتو افر وسائل النقل الجوى ألخاصة بخدمة السياحة الرياضية بصورة كافية ؟ & \\
\hline$\% \wedge 1 . \wedge r$ & r & 9 & الخدمات الطبية أثناء ممارسة الأنشطة الرياضية السياحية ؟ & $r \cdot$ \\
\hline
\end{tabular}

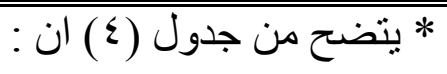

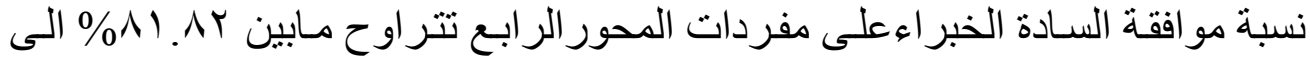

$$
. \% 9 \cdot .91
$$

ثبات استبيان السياحة الرياضية:

استخلم الباحثون طريقة التجزئة النصفية لسبيرمان براون و معادلة جتمـان العامـة للتجزئسة النصـفية لحسـاب معامـل ثبـات اســمارة الاسـتبيان للتأكد من ثبات نتائج الاستبيان بإعادة تطبيقه مرة أخري بفاصل زمني مقداره 10 يوم علي • ب فرد من أفراد عينة البحث الكلية (العينة الاستطلاعية) لإيجاد معامل الارتباط بين كل من القياس الأول والثاني لكل بعد كما هو موضـح بالجدول التالى: لإنى

$$
\text { جدول (0) }
$$

\begin{tabular}{|c|c|c|c|c|}
\hline جتمـان & \multicolumn{2}{|c|}{ سبيرمان براون } & \multirow{2}{*}{ المحور } & \multirow{2}{*}{ e } \\
\hline الثبات & الثبات & الارتباط & & \\
\hline .940 & $.9 r r$ & $* . \wedge \vee r$ & الاول & 1 \\
\hline$\cdot .9 \cdot 1$ & $\because \wedge \wedge \wedge$ & *. . $\vee 9 \wedge$ & الثانى & $r$ \\
\hline .991 & .900 & $* . .91 \leq$ & 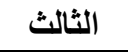 & $r$ \\
\hline $.9 \leq 1$ & $\cdot .9 \leq r$ & $* . . \wedge 9 \%$ & الرابع & $\varepsilon$ \\
\hline .901 & $\cdot .9 \leq 1$ & $* \cdot .9 \cdot 1$ & الاستبيان & 0 \\
\hline
\end{tabular}

ثبات الاستبيان قيد البحث 
* دال

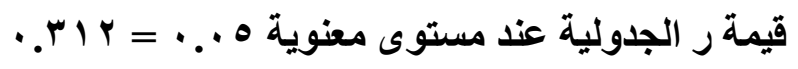

يتضح من جدول (0) ثبات استمارة الاستبيان ومحاور ها حيث بلغ معامل ثبات

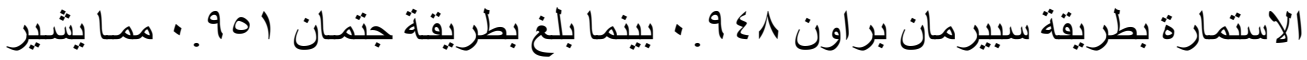

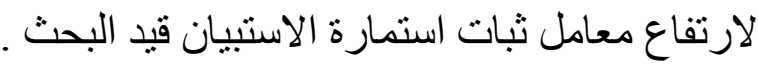

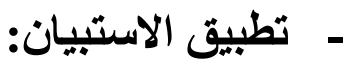

قام الباحثون بتطبيق الاستبيان في صورته النهائية علي أفراد العينة وحدد

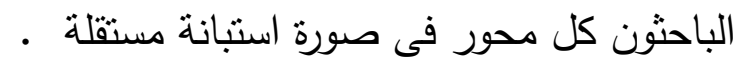

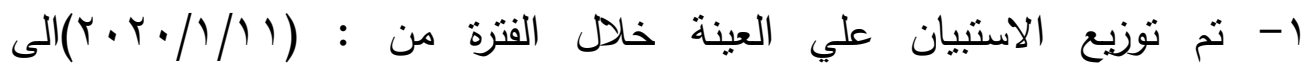

$$
\cdot(r \cdot r \cdot / \varepsilon / r \cdot)
$$

r - تم شرح محتوى استبيان البحث للعينة وتوضيح الهدف منه، كما تم شرح أسلوب الإجابة علي العبارات وتقسير أية مفردات غير واضحة بالنسبة لأفراد العينة . r- لضمان الموضوعية في البيانات راعى الباحثون بأن يكون كتابة الاسم اختياريا،

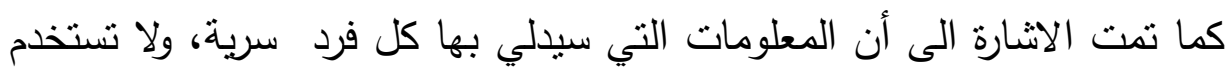

$$
\text { إلا لغرض تحقيق أهداف البحث العلمي فقط . }
$$

ع - قام الباحثون بجمع استبانات كل محور فى استبانة واحده بعد التطبيق.

\section{المعالجة الاحصائية : الإحنية}

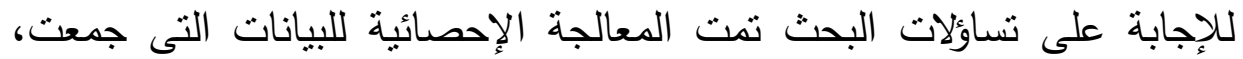
واستخدم برنامج الحزم الإحصائية للعلوم الاجتماعية SPSS لإجراء الإنة الإنة المعالجات

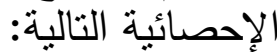

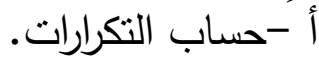

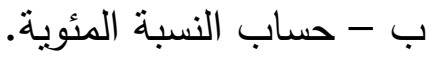

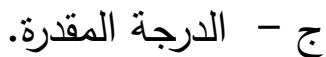

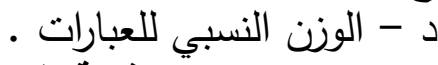
عرض وتفسير ومناقشة النتائج:

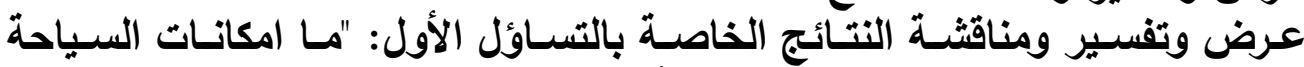

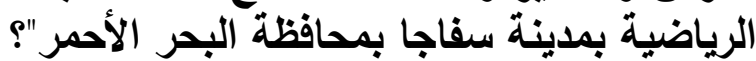

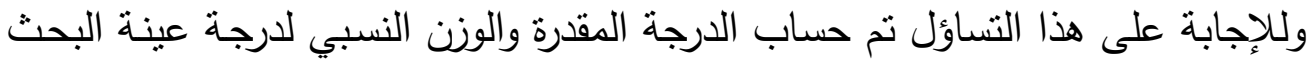
على عبارات استبيان السياحة الرياضية ورصدت نتائج ذلك فى الجدول التالي : 


\section{جدول(7)}

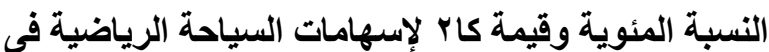

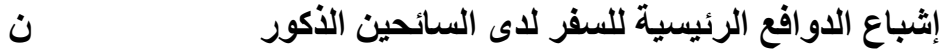

$7 V \cdot=$

\begin{tabular}{|c|c|c|c|c|c|c|c|c|c|c|c|}
\hline \multirow[t]{2}{*}{ التزتيب } & \multirow[t]{2}{*}{ كاץ } & \multirow[t]{2}{*}{ النسبة } & \multirow{2}{*}{ التقديرية } & \multicolumn{2}{|c|}{ ت ضعاهم بلرجة } & \multicolumn{2}{|c|}{ ت متوسطة بلرجة } & \multicolumn{2}{|c|}{ تساهم بلرجة } & \multirow[t]{2}{*}{ الأقع } & \multirow[t]{2}{*}{ r } \\
\hline & & & & نسبة & عدد & نسبة & عدد & نسبة & عدد | عد | & & \\
\hline 1 & $V .0 .1$ & $\% 91.7 \mathrm{~V}$ & $1 \wedge \leq r$ & $\% .7$. & $\varepsilon \varepsilon$ & $\% 11.1$. & vq & $\% \wedge 1.7$. & $0 \leqslant V$ & الطبيعة بالممارسة في أحضان & 1 \\
\hline$r$ & $\mathrm{~V} . \mathrm{V}$ & $\% \wedge \varepsilon . Y$. & 794 & $\% \cdot \ldots$ & - & $\% \varepsilon \vee . \varepsilon$. & MIN & $\%$ \%. . . & ror & مصاحبة الأسرة . & $r$ \\
\hline 7 & IVV.Y & $\% \wedge \cdot . Y V$ & $171 \%$ & $\% 10 . \wedge$ & 1.7 & $\%$ YV. . & $1 \wedge 0$ & $\% 07.7$. & $r v q$ & الراحة والاستجمام . & $r$ \\
\hline iv & .9 & $\% .7$ & 7 & $\%$ & ros & - & $r \cdot r$ & 7. & rir & معين. التدريب على نثـاط رياضسى & $\varepsilon$ \\
\hline $1 \leq$ & $\leqslant 0 . Y$ & $\% \vee V I . r$ & $1 \leqslant Y \wedge$ & $\% 1.7$. & YIY & \%rr.v. & 109 & $\% \leq \varepsilon . V$. & rq9 & مراققة الزملاء . & 0 \\
\hline$\Lambda$ & $19 V .1$ & $\% \vee \wedge .0$ & $10 V A$ & $\%$. . . & or & $\% \varepsilon \wedge . \vee$. & PrY & $\% \varepsilon \Psi . \varepsilon$. & rq1 & الإنجــــــاز . & 7 \\
\hline 11 & $r 9.0$ & $\% 7 \cdot .94$ & IrYo & $\% \varepsilon \varepsilon . V$. & r.. & $\%$ \% . . & 110 & \%.Y. . & 110 & دوافع & $\mathrm{V}$ \\
\hline 0 & $19 \vee . \wedge$ & $\% \Lambda \cdot . r V$ & $171 \%$ & $\% \vee .9$. & $\Delta r$ & $\% \varepsilon \Psi . \varepsilon$. & 191 & $\%$ \% . $\vee$. & rrt & دوافع ثقافية . & $\Lambda$ \\
\hline$\varepsilon$ & 0 & $\% \wedge r . \mu$ & $17 \leqslant 9$ & $\% r q . r$. & 187 & $\%$..$\mu$. & 9 & $\% \vee r . \varepsilon$. & $\leqslant \wedge 0$ & 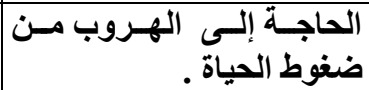 & 9 \\
\hline 1. & Ar.V & $\% \vee \bullet . \wedge \mathrm{V}$ & $10 Y 0$ & $\% 1 \mathrm{~V} .1$. & 110 & $\% \mu \wedge . r$. & roq & $\% \varepsilon \varepsilon . V$. & r99 & اكتشاف النفس . & 1. \\
\hline 10 & IV.V & $\% 79.4$. & Irqr & \%.Y.r. & 187 & $\% r q .0$. & YYo & $\%$ \%.r. & rrq & المخاطـــرة . & 11 \\
\hline ir & 111.0 & $\% \vee 1.0$ & $1 \leqslant \mu V$ & $\% 1 \mathrm{~V} .1$. & 110 & $\% 01 . \mu$. & $r \leq \varepsilon$ & $\% 1.7$. & YIr & 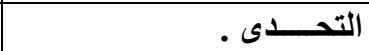 & Ir \\
\hline V & 101.1 & $\% \vee \wedge .9 \vee$ & $10 \wedge V$ & $\% \wedge . \varepsilon$. & ITr & $\%$ \% . r. & 187 & $\% \circ 0 . \mu$. & mvi & البحث عن كل ما هو جديد . & ir \\
\hline$r$ & $Y 10$. & $\% \wedge r . r$ & $17 \leq 9$ & $\%$ \%. . . & $7 r$ & $\%$ \%.0. & rrA & $\% \Delta 0 . \mu$ & rvi & التسلية والترفيه . & $1 \varepsilon$ \\
\hline ir & $\leq 7 . r$ & \%VY.YA & $1 \leqslant V Y$ & $\%$ \% 1.1 & $1 \leq 1$ & $\%$ \%.r. & roT & $\% \varepsilon \cdot . \wedge$. & rVT & ارتياد أماكن جديلة . & 10 \\
\hline 11 & 19.7 & $\% \vee 0^{\prime} .$. & $10 \cdot 1$ & $\% 1 \mathrm{~V} .1$. & 110 & $\% \varepsilon \cdot . \wedge$. & rVT & $\% \varepsilon Y .1$. & $r \wedge r$ & التجديد . & 17 \\
\hline 17 & Irr.q & $\% 7 v .0 \%$ & Irov & $\% \varepsilon r .1$. & $r \wedge r$ & \% Ir.Y. & $\Lambda \wedge$ & $\% \varepsilon \varepsilon . V$. & 199 & العلاج البلنى ـ & IV \\
\hline 19 & 1.7 .0 & $\% 09.10$ & 1119 & $\% 01 . \mu$. & $r \leq \varepsilon$ & $\% 19.2$. & Irr & $\%$ \%. 9 . & $19 \varepsilon$ & العلاج النفسى . & 11 \\
\hline 9 & $\varepsilon \cdot r . r$ & \% & 10TE & $\%$ & IV & $\Lambda$. & $\varepsilon \leqslant 1$ & 7. & $Y ו r$ & الآخرين . علاقــات وروابط مـعـ & 19 \\
\hline
\end{tabular}

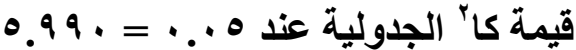

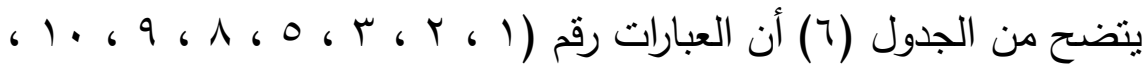

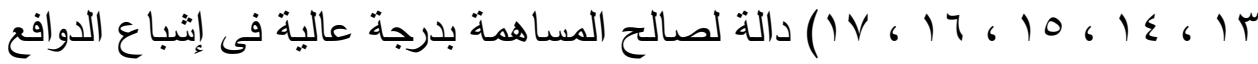

الرئيسية للسفر لاى السائحين الذكور الوافدين الى جمهورية مصر العربية ـ حيث أن

قيمة كاب المحسوبة اكبر من قيمتها الجدولية عند مستوى دلالة ه ... . 
- والعبارات رقم (7 ، 1 1 ، ب 1 ، 9 ( ) دالـة لصـالح المسـاهمة بدرجـة منتوسطة في إثـباع الـوافع الرئيسية للسفر للدى السـائحين الذكور الوافدين الى جمهوريـة مصـر العربيـة ـ حيث أن قيمـة كاب المحسوبة اكبر من قيمتها الجدوليـة عند مستوى دلالـة

- والعبارات رقم (ع ، V ، 1 1 ) دالة لصالح المساهمة بدرجة ضعيفة فى إثباع الدوافع الرئيسية للسفر لدى السائحين الذكور الوافدين الى جمهورية مصر العربية . حيث أن قيمة كاب المحسوبة اكبر من قيمتها الجدولية عند مستوى دلالة هـ ـ. . . ويرجـع البـاحثون هذه النتائج إلى عدم تـوفر كافة الأنشطة الرياضية بالمشـروعات السياحية في جمهوريـة مصر العربية مما يجعل السياحة الرياضية تؤثز على تتشيط حركة الانتاج والاستثمار في مجال الرياضة والمجالات الاخري وكذلك يؤثر على نقل العادات والتقاليد بين السائحين وسكان مصر •

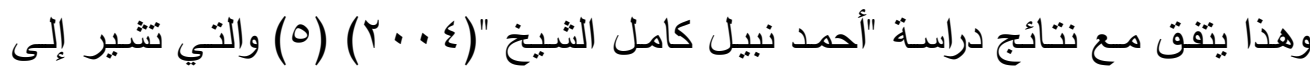
تهدف السياحة الرياضية إلى استثمار المقومات الطبيعية المتوفرة فى جمهورية مصر العربية لتتميـة الموارد بالاتحادات الرياضية في مصر تهدف السياحة الرياضية إلى لى الاستثمار الامتل المتوفرة لتتمية الموارد .

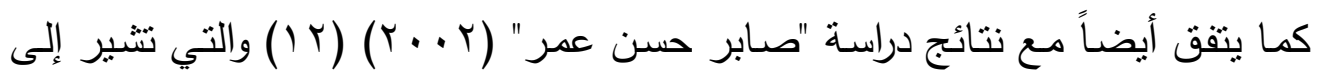
ارتفاع تكلفة ممارسة بعض مناشط الترويح المائي ،عدم توافر عوامل الأمن والسلامة وعدم توفر كافة مناشط الترويح المائي •

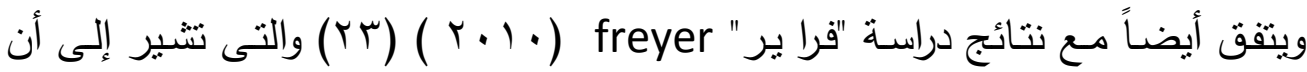

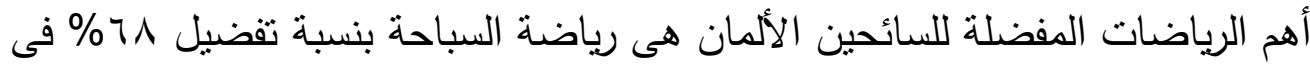

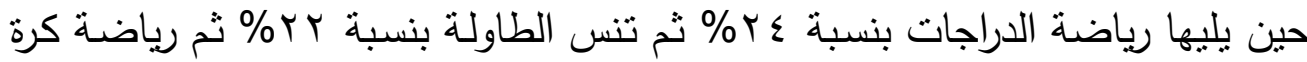
القدم بنسبة ؛ (\% فى حين تأتى فى نهايـة تلك الرياضـات المفضلة كل من تسلق الجبال والتتس والكرة الطائرة بنسبة مئوية قدرها 9 (1\% ـ 
وبهذا يتم الإجابة على التساؤل الأول والذي ينص على ما ما امكانات السياحة الرياضية بمدينة سفاجا بمحافظة البحر الأحمر؟

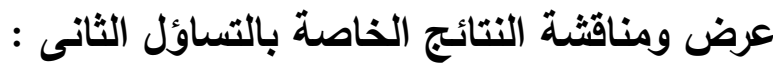

ينص هذا التساؤل على "ما معوقات ومشكلات السياحة الرياضية بمدينة سفاجا

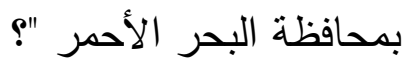

وللإجابة على هذا التساؤل تم حساب الدرجة المقدرة والوزن النسبي لدرجة عينة البحث على عبارات استبيان السياحة الرياضية ورصدت نتائج ذلك فى الجدول التالي :

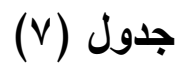

إسهامات السياحة الرياضية فى إثباع الدو افع الرئيسية للسفر لاى السائحين

\begin{tabular}{|c|c|c|c|c|c|c|c|c|c|c|c|}
\hline \multirow[t]{2}{*}{ الترتيب } & \multirow[t]{2}{*}{ كاY } & \multirow[t]{2}{*}{ النسبة } & \multirow{2}{*}{ التقديرية } & \multicolumn{2}{|c|}{ تساهم بلرجة } & \multicolumn{2}{|c|}{ تساهم بلرجة } & \multicolumn{2}{|c|}{ تساهم بلرجة } & \multirow[t]{2}{*}{ الدافع } & \multirow[t]{2}{*}{ م } \\
\hline & & & & نسبة & عدد & نسبة & عدد & نسبة & عدد & & \\
\hline r & $109 . V$ & $\%$ \%r. & $\wedge r \wedge$ & $\% .71$ & $r$ & $\% \varepsilon \vee . \wedge \wedge$ & 101 & $\% \circ 1.0 r$ & IV. & الطبيعة بالممارسـة فى أحضـان & 1 \\
\hline 7 & 94.9 & $\% \cdot \Lambda \cdot . r$ & $V q \leq$ & $\% \wedge . \leqslant \wedge$ & $r \wedge$ & $\% \leqslant Y$. $\{Y$ & $1 \leq$. & $\% \leqslant 9.99$ & $17 r$ & مصاحبة الأسرة & $r$ \\
\hline 1 & $r \cdot V_{0}$. & $\% 9 \cdot . \cdot$ & 191 & $\% \wedge . \vee q$ & rq & $\%$ Y Y \& Y & $\leqslant 1$ & $\% \vee \wedge . \vee q$ & rq. & الراحة والاستجمام & $r$ \\
\hline iv & 0.0 & \%.ィ & TrY & $\%$ \% . & ir. & $\%$ \%. v. & $9 \wedge$ & $\% r \cdot .91$ & $1 \cdot r$ & |التــريب علـى نشـاط رياضسي & $\varepsilon$ \\
\hline 11 & Y.0 & $\% \vee v r .0$ & $V Y \Lambda$ & $\% r \cdot \ldots$ & 79 & $\%$ \%q.rq & IT. & $\% \varepsilon \cdot .71$ & ITs & مر افقة الزملاء & 0 \\
\hline Ir & 19.1 & $\% \vee Y_{.0}$ & $\vee 1 \wedge$ & $\%$ \% I.AY & VY & 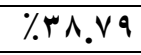 & $1 \% 1$ & $\%$ rq.rq & $1 \%$ & الإنجـــــــاز & 7 \\
\hline 11 & $1 \leqslant$. & $\%$ \%.V & 711 & $\% \varepsilon r . \mu$ & $1 \leqslant r$ & $\% \curlyvee \wedge . \vee q$ & 90 & $\% \curlyvee \wedge . \mid \wedge$ & $q \mu$ & دوافع مهنية & v \\
\hline V & $\wedge \wedge .9$ & $\% \wedge \cdot .1$ & Var & $\% 17.9 \mathrm{~V}$ & 07 & \%००.VT & 10 & $\% \Delta V . Y V$ & 119 & دوافع ثقافية & $\Lambda$ \\
\hline 0 & 10.9 & $\% \wedge \cdot . r$ & $\vee 90$ & $\% 10.10$ & o. & $\% \curlyvee \wedge . \vee q$ & 90 & $\% 07.97$ & 110 & ضغوط الحياة إلـى الهــروب مــن & 9 \\
\hline 17 & $0 \wedge .7$ & $\%$ \%. & IVO & $\% \varepsilon \cdot .91$ & 110 & $\% 1$. . $1 \leq$ & $\leqslant 0$ & $\% \leqslant 0 . \leqslant 0$ & 10. & اكتشاف النفس & 1. \\
\hline 10 & $0 . r$ & $\%$ \%.\& & IVV & $\% \curlyvee \wedge .1 \wedge$ & 94 & $\% \mu \wedge . \leqslant \wedge$ & IYV & \% & 11. & المخاطــرة & 11 \\
\hline 14 & $0 \cdot .0$ & $\% v \cdot . \varepsilon$ & $79 V$ & $\% 19.99$ & 74 & $\% 0 \cdot .71$ & 178 & $\% r \cdot r \cdot r \cdot$ & $1 \ldots$ & التـــــــى & Ir \\
\hline 1. & $\leq \leqslant .1$ & $\% \vee ५ . r$ & Vos & $\% 17.7 \mathrm{~V}$ & 00 & $\% r \vee . \wedge \wedge$ & $1 \% 0$ & $\% \leqslant 0 . \leqslant 0$ & 10. & البحث عن كل ما هو جديد & 14 \\
\hline$\Lambda$ & $110 . r$ & $\% \vee 9 . r$ & $\vee \wedge \bullet$ & $\% 0.17$ & 19 & $\% 0 \cdot .71$ & $17 V$ & $\% \leq 4.7 \leq$ & $1 \leq \varepsilon$ & التسلية والترفيه & $1 \leq$ \\
\hline$\varepsilon$ & $1 Y 1.9$ & $\%$ \%r.1 & Arr & \%.YV & $r \varepsilon$ & $\% \% 4.97$ & 119 & $\% 07.7 \mathrm{~V}$ & $1 \wedge \mathrm{V}$ & |رتياد أماكن جديدة & 10 \\
\hline 9 & 177.8 & $\%$ \%1. & $\Lambda \cdot \Lambda$ & $\% \cdot r \cdot r$ & 1 & $\% 0 \leqslant .00$ & $1 \wedge$ & $\% \leqslant 0.10$ & $1 \leqslant 9$ & |التجديد & 17 \\
\hline $1 \leq$ & rr.t & $\% v \cdot . r$ & 797 & \%rr.rr & 11. & \%YY.\&Y & $V \varepsilon$ & $\% \leqslant \varepsilon . Y \leqslant$ & $1 \leq 7$ & العلاج البدني & IV \\
\hline 19 & $7 \leqslant .0$ & $\% \circ \vee .9$ & oVr & $\% \circ r .7 \leq$ & IVV & $\% 19.99$ & 74 & \%rV.rv & 9. & العلاج النفسي & 11 \\
\hline$r$ & $r v \leq .1$ & \%.یr.r & Aro & $\% Y \leq . Y \leq$ & $\Lambda$. & $\% 1.0 Y$ & 0 & $\% \vee \leq \leq \leq$ & $r \leqslant 0$ & الآخرين تكـوين علاقـات وروابـط مـع & 19 \\
\hline
\end{tabular}




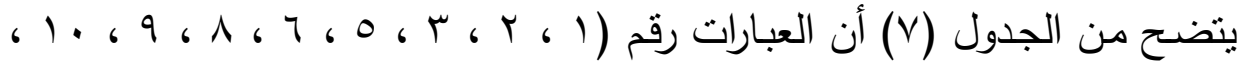
r 10 ، 10 ، V V ، 9 ( ) دالة لصالح المساهمة بدرجة عالية فى إثباع الدوافع الرئيسية

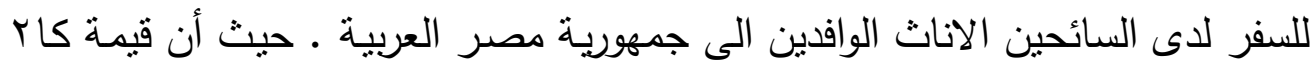
المحسوبة اكبر من قيمتها الجدولية عند مستوى دلالة ه . . . .

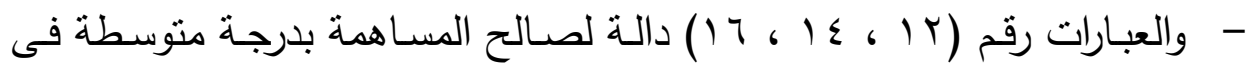
إثـباع الدوافع الرئيسية للسفر للدى السـائحين الانـاث الوافدين الى جمهوريـة

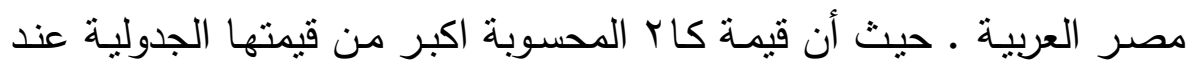

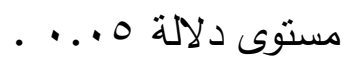

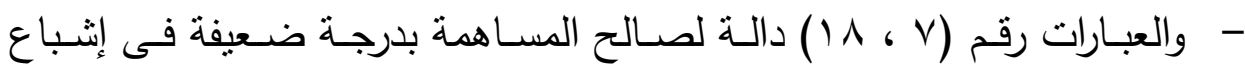
الدوافع الرئيسية للسفر لـى السـائحين الانـاث الوافدين السى جمهوريـة مصـر

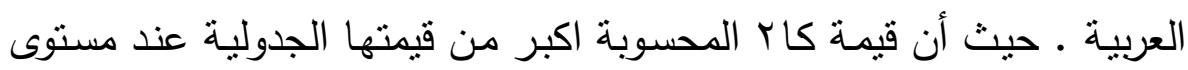

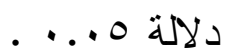

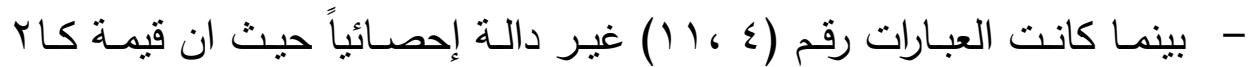
المحسوبة اقل من قيمتها الجدولية عند مستوى دلالة هـ.. . . ويرجع الباحثون هذه النتيجة إلى أنه قد تهنم الدولة بأمور أخري في البلد وقلة الاهتمام بتتشيط السياحة الرياضية وتقل العاملين على تقديم هذه الخدمة للسائحين حيث لم يتم

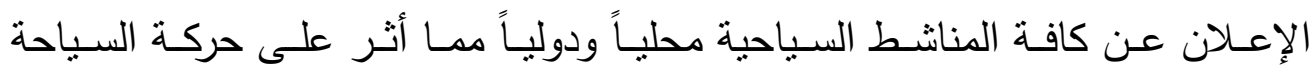
الرياضية في مصر فالاهتمام ببرامج السياحة الرياضية وتتوعها والاعلان عنها بشكل جيد ينعكس بدورة على تفعيل السياحة الرياضية والاستثمار في كافة المجالات .

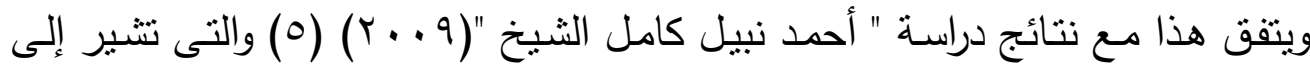
تقويم البرامج الترويحية الرياضية المقترحة لتفعيل السياحة الرياضية للوقوف على مدى كفاءة هذه البرامج ومدى تعـاظم الفائدة المرجـوة مـن وجودهـا فـى البرامج السياحية للمساعدة فى تحقيق الرسالة الترويحية للقرى والفنادق بالمدن السياحية المصرية . 


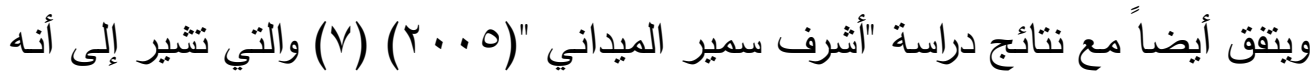
لا يتوفر في مصر الأخصائيون القادرون على العمل في مجال السياحة الرياضية كما تشير نتائج هذه الدراسـة إلى وجود قصور في أداء الجهات الإعلاميـة في دورها في لئي نجاح السياحة الرياضية المصرية كما يعتبر الإعلام والتسويق من الإمكانات الهامـة والمؤثرة في نجاح السياحة الرياضية في مصر • كما يتفق مع منظمة السياحة العالمية واللجنة الأولمبية الدولية وزارة السياحة ( . . ب) (1) (1)، حيث أكداعلى أن السياحة والرياضـة أداتان قويتان للتتمية وزيادة الإستثمارات في مشروعات البنية الأساسية مثل المطارات والطرق والإستادات والمجمعات الرياضية والفنادق والمطاعم.

ويتفق أيضاً مع نتائج دراسة " أبو بكر عوني عطية علي "(r ( + ( ) ( ) والتى تثير إلى تشجيع الفرق الأجنبية للقدوم إلى البلاد لإقامة معسكرا تهم التدريبية بها بما يسهم فى الارتقاء بالسياحة الرياضية، وضع خطة قومية للاستفادة من زيادة أعداد السائحين الوافدين . وبهذا يتم الإجابة على التساؤل الثاني والذي ينص على ما معوقات ومشكلات السياحة

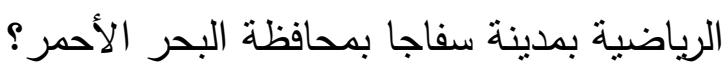
عرض ومناقشة النتائج الخاصة بالتساؤل الثالث :

ينص هذا التساؤل على ما الامكانات المادية والبشرية في مجال السياحة الرياضية ؟ وللإجابة على هذا التساؤل تم حساب الدرجة المقدرة والوزن النسبي لدرجة عينة البحث على عبارات استبيان السياحة الرياضية ورصدت نتائج ذلك فى الجدول التالي: 


\section{جلول (^)}

أهم الامكانات المستخدمة فى السياحة الرياضية

بمصر طبقاً لر أى السائحين

\begin{tabular}{|c|c|c|c|c|c|c|c|c|c|c|c|}
\hline \multirow{2}{*}{ الترثيب } & \multirow{2}{*}{ كاr } & \multirow{2}{*}{ النسبة } & \multirow{2}{*}{ الثدرجة الثمبرة } & \multicolumn{2}{|c|}{$y$} & \multicolumn{2}{|c|}{ الحى حد مـا } & \multicolumn{2}{|c|}{ تعم } & \multirow{2}{*}{ العبارة } & \multirow{2}{*}{ م } \\
\hline & & & & نسبة & عدد & نسبة & عدد & نسبة & عدد & & \\
\hline 10 & $9 r . V$ & $\% \vee \curlyvee . \wedge$. & $1 \leq 74$ & $\% 1 \vee .1$. & 110 & $\% \varepsilon V . \varepsilon$. & M & $\%$ \%०.०. & rrA & في مجال السياحة الريادات الرياضية المؤهلة للعمل & 1 \\
\hline 18 & $\wedge \neg . r$ & $\%$ VI.Or & $1 \leq r \Lambda$ & $\% \wedge \wedge . \vee$ & 1ro & $\% \leqslant \wedge$. & MrY & • ש.r.r. & rrr & 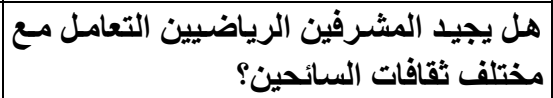 & $r$ \\
\hline $1 \varepsilon$ & Yrq.\& & \% VY.Ar & $1 \leq 7 \leq$ & $\%$ \%.А. & $r \leqslant V$ & $\% \vee .9$. & or & \%००.r. & rvi & 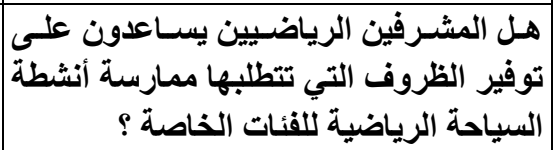 & r \\
\hline 9 & r. $\varepsilon_{.}$ & $\% \vee \bullet \wedge r$ & IOY & $\% q . r$. & $9 Y$ & $\% \circ r . q$. & Mq & $\%$ \%.^. & $r \leqslant V$ & 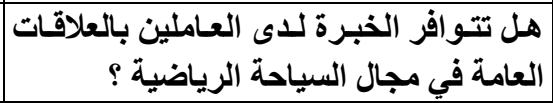 & $\varepsilon$ \\
\hline$r$. & $1 \varepsilon . r$ & \%ฯr.v. & $1 Y 7$. & $\%$ \%.०. & Y7o & $\%$ \% r.q. & $r r$. & $\%$ \% . . & 110 & 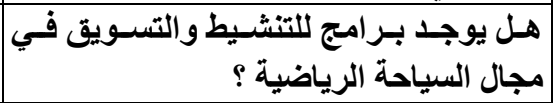 & $\bullet$ \\
\hline 17 & $r \cdot . \Lambda$ & \%VY.rV & $1 \leq 00$ & \%rr.v. & 109 & $\%$ \% •.०. & rrA & $\% \varepsilon \cdot . \wedge$. & rVY & 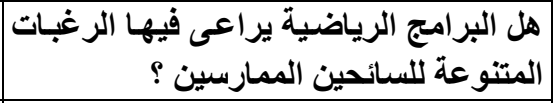 & 7 \\
\hline 19 & $r \leq . r$ & \%.r.IV & IrV. & $\% r \varepsilon . r$ & rrq & $\% \varepsilon Y_{.}$. & rAr & $\% r r . V$. & 109 & 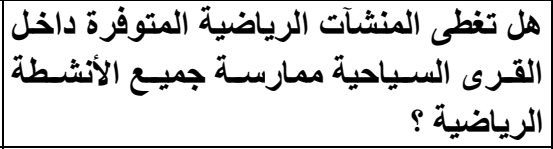 & V \\
\hline 1. & $v \cdot . v$ & $\% \vee \bullet . \leqslant \wedge$ & 1018 & $\%$ \% I. & $1 \leq 1$ & $\%$ \% . . & YIr & $\% \leqslant V_{.} \varepsilon$. & $M$ & مارسة & $\Lambda$ \\
\hline$\Lambda$ & I $\mathrm{H} . \mathrm{r}$ & $\% \vee \vee . । \wedge$ & 1001 & $\% \curlywedge 1 . \wedge$. & $\Lambda$. & $\% \varepsilon \varepsilon . \vee$. & rqq & $\% \leqslant r . \leqslant$. & YqI & 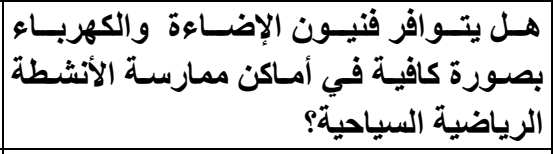 & 9 \\
\hline Ir & VY.V & $\%$ r.v. & $1 \leq \wedge 1$ & $\% r \vee\urcorner$. & 110 & \%rr.v. & 109 & $\%$ $\leqslant$. $\vee$. & rrq & الرياضية بصنوافر فنيون صيانة الأدوات والأجهزة & \\
\hline 11 & $r \varepsilon . q$ & $\% \curlyvee \wedge . \wedge \mathrm{V}$ & $1 T \wedge \varepsilon$ & $\%$ \%०... & 171 & $\% \leqslant \Psi . \varepsilon$. & Yq1 & $\%$ \% . . & YIr & 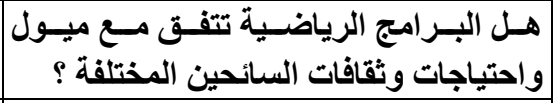 & 11 \\
\hline Ir & $\wedge \wedge .1$ & \%r.rr & $1 \leqslant V Y$ & $\% 1 \vee .1$ & 110 & $\% \leqslant 7.1$. & r. $q$ & $\%$ \%.А. & $r \leq V$ & 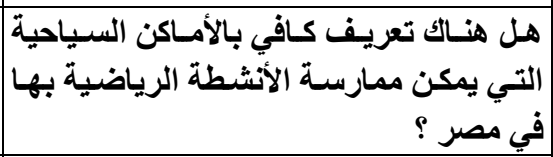 & Ir \\
\hline 0 & $19 \cdot . r$ & $\% \wedge 1.1 \mathrm{~V}$ & 1741 & $\% \curlywedge 1 . \wedge$ & Vq & $\%$ \%r.q. & $r r$. & $\% \bullet \bullet . r$. & HVI & 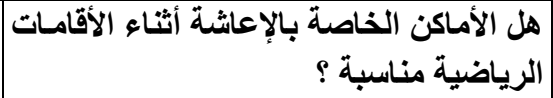 & n \\
\hline
\end{tabular}




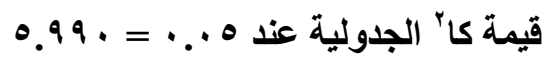

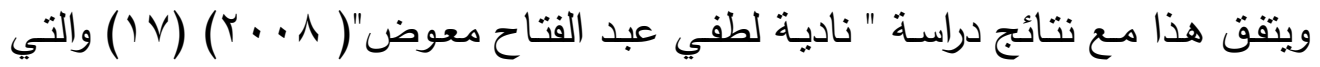
تشـير إلـى تـوافر الإمكانـات الماديـة والبشـرية يسـاعد على إقامـة البـرامج الرياضـية

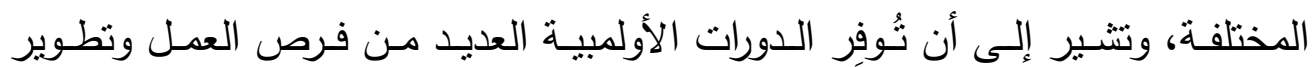

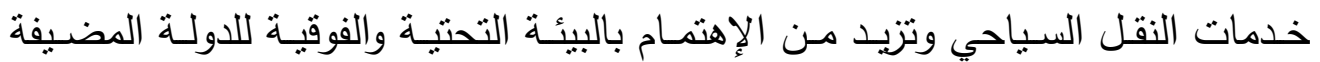

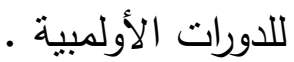
ويتفق أيضاً مع نتائج دراسة " أحمد نبيل كامل الثيخ " (ع . . r) (T) والتي تشير إلى أنه لاتوجد برامج للسياحة الرياضية موضوعة من قبل الإتحادات الرياضية ، وأنه لايتم الإستفادة من الخبراء والمسئولين في كليات التربية الرياضية وكليات السياحة والفنادق عند وضع برامج السياحة الرياضية التي تشرف عليها الإتحادات الرياضية في مصر • وبهذا يتم الإجابة على التساؤل الثالث والذي ينص على الامكانات المادية والبشرية في مجال السياحة الرياضية ؟ عرض ومناقشة النتائج الخاصة بالتساؤل الرابع : ينص هذا التساؤل على ما التحديات المعاصرة التى تؤثز على السياحة الرياضية محلياً وعالمباً؟ ولإجابة على هذا التساؤل تم حساب الدرجة المقدرة والوزن النسبي لدرجة عينة البحث على عبارات استبيان السياحة الرياضية ورصدت نتائج ذلك فى الجدول التالي: 


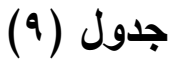

أهم الامكانات المستخدمة فى ترويج السياحة الرياضية

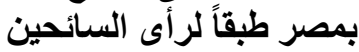

\begin{tabular}{|c|c|c|c|c|c|c|c|c|c|c|c|}
\hline \multirow{2}{*}{ الترتيب } & \multirow{2}{*}{ كا' } & \multirow{2}{*}{ النسبة } & \multirow{2}{*}{ التقديرية } & \multicolumn{2}{|c|}{ ل } & \multicolumn{2}{|c|}{ الى حد ما } & \multicolumn{2}{|c|}{ نعم } & \multirow{2}{*}{ العبارة } & \multirow{2}{*}{ b } \\
\hline & & & & نسبة & عدد & نسبة & عدد & نسبة & عدد & & \\
\hline$\varepsilon$ & Irr.r & $\% \wedge 1.9$ & 111 & $\% 17.97$ & or & \%rr.Ir & $v^{\mu}$ & $\% \neg . \wedge r$ & $r \cdot \varepsilon$ & 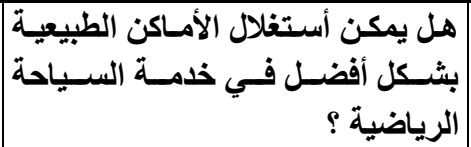 & $\begin{array}{l}1 \\
\varepsilon\end{array}$ \\
\hline v & $90 . V$ & $\% \vee \wedge . \vee q$ & $\vee \wedge$. & $\% 1 \leqslant .00$ & $\leqslant \wedge$ & $\% r \varepsilon .00$ & $11 \leq$ & $\% 0.91$ & 191 & 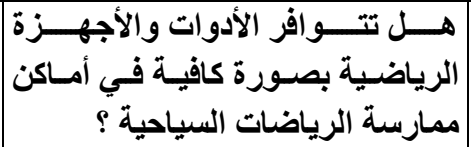 & $\begin{array}{l}1 \\
0\end{array}$ \\
\hline$r$ & 19.1 & $\% \wedge \cdot . \wedge 1$ & $\wedge \ldots$ & $\% 1 r .14$ & $\varepsilon$ & r.r.r. & 11. & $\% 0 \leqslant .00$ & $1 \wedge$ & 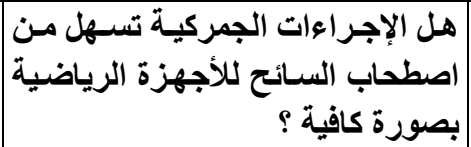 & $\begin{array}{l}1 \\
7\end{array}$ \\
\hline$\wedge$ & $\Lambda \vee . r$ & $\% \vee \wedge . \vee q$ & $\vee \wedge$. & $\% 9.9$ & $\mu$. & $\% \leqslant 0 . \leqslant 0$ & 10. & $\% \leqslant 0 . \leqslant 0$ & 10. & 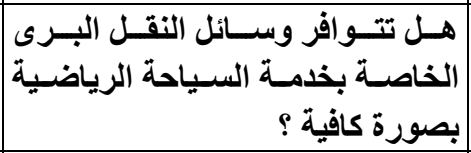 & $\begin{array}{l}1 \\
v \\
\end{array}$ \\
\hline 1 & m $19 . \mathrm{V}$ & \% १r.or & 917 & $\% \cdot .71$ & r & $\%$ \%I.YI & $v$. & $\% \vee \wedge .1 \wedge$ & $r \otimes \Lambda$ & 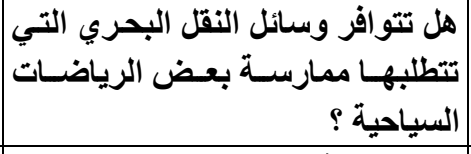 & $\begin{array}{l}1 \\
\Lambda \\
\end{array}$ \\
\hline 0 & $90 .$. & $\%$ \% . r & 1.0 & $\% 11.70$ & $\mu \Lambda$ & \%rr.q. & 1.9 & $\% \Delta 0 . \leqslant 0$ & $1 \wedge r$ & 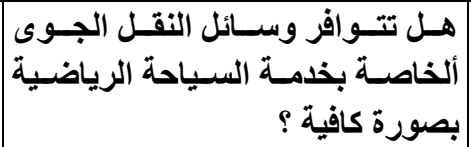 & $\begin{array}{l}1 \\
9\end{array}$ \\
\hline 11 & rr.l & $\% 9 \wedge .9$ & $\checkmark \wedge r$ & $\% r r . q \leq$ & $v q$ & $\% \leqslant 0.10$ & $1 \leq 9$ & $\% r \cdot .91$ & $1 \cdot r$ & | السياحيةج & r \\
\hline
\end{tabular}

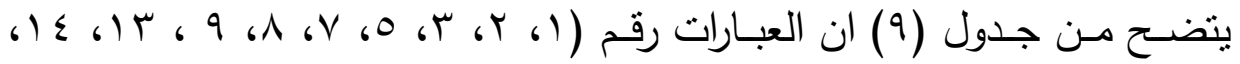

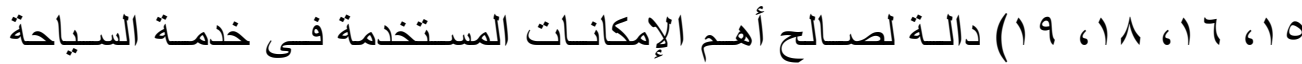
الرياضية فى مصر طبقاً لرأى السائحين الإناث الوافدين الى جمهوريـة مصر العربية عند مستوى معنوية ه . . • لصالح الإجابة بنعم •

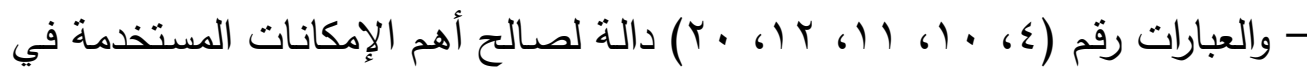
خدمة السياحة الرياضية فى مصر طبقاً لرأى السائحين الإناث الوافدين الى جمهورية 
مصر العربية . عند مستوى معنوية ه . . لصالح الإجابة ب( الى حد ما).-- والعبارة

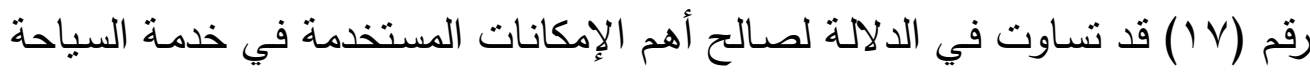

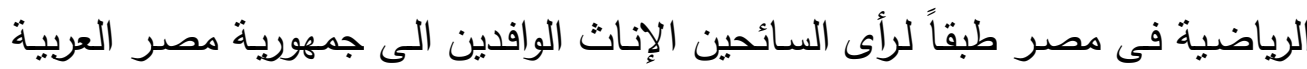
عند مستوى معنوية ه . . . لصالح الإجابة بنعم ،الى حد ما .

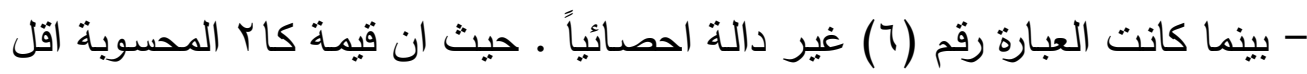
من قيمتها الجدولية عند مستوى دلالة ه. .. .

يرجع الباحثون هذه النتيجة إلى الظروف السياسية والاقتصـادية التى تمر بها مصر

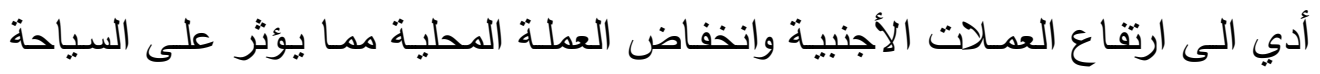
الرياضية بشكل واضـح نتيجة عدم الاقبـال على ممارسـة مناشط السياحة الرياضية منتيجة الاضطرابات التى تمر بها مصر مما ينتج عنها من أعمال العتف والارهاب .

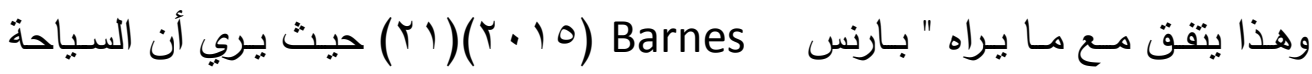

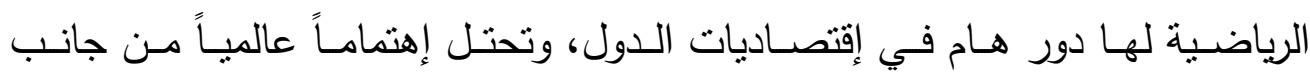

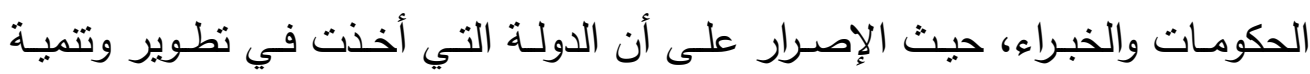
القطاع السياحي فيها تأخذ طريقها نحو التتمية الإقتصادية وتحسين الهيكل الاقتصادي ويظهر ذلك في زيادة الإيرادات السياحية من النقد الأجنبي مما يعطي الدفعة اللازمة للتتمية بتوفير أكبر قدر من العملات الأجنبية التي ينفقها السائحون خلال مدة إقامتهم

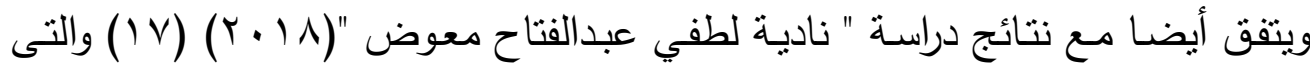
تشـير الـى توفر الدورات الاولمبيـة العديـد مـن فرص العمل وتطوير خدمات النقل السياحي مما له تأثنير ايجابي على اقتصاد الدولة المستضيفة. وبهذا يتم الإجابة على التساؤل الرابع والذي ينص على ما التحديات المعاصرة التى تؤثز على السياحة الرياضية محلياً وعالمياً؟ 


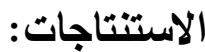

أولاً : فيما يخص واقع السياحة الرياضية في جمهورية مصر العربية السياحة الرياضية تؤثر بشكل كبير على: - البيئة الاجتماعية والثقافية من خلال تبادل الثقافات بين السائحين وسكان المدن. - - نسويق السلع والمنتجات الصناعية من خلال قلة تردد السائحين على هذه

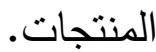
- توفير فرص عمل جيدة ضمن حدود القطاع السياحي . ثنانيا : فيما يخص معوقات ومشكلات السياحة الرياضية - عدم وجود تثريع خاص بالسياحة الرياضية ضمن مجالات الاستثمار والتتمية - - معوبة تسويق برامج وأنشطة السياحة الرياضية .

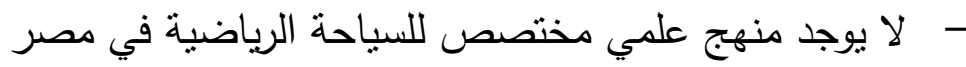
- قلة اهتمام شركات السياحة بالاعلان والدعاية عن الأنثطة والبرامج الخاصة مصنة بالسياحة

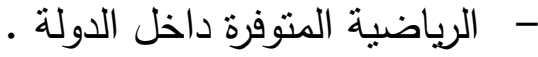

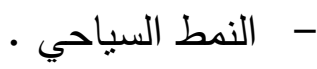
- الافتقار لوجود سياسة تسويقية قادرة على توجيه المنتج السياحى الرياضى لئي بشكل يتناسب مع رغبات السوق المستهدف. - - عدم توافر خدمات اعلامية كافية عن الدسابقات الرياضية العالمية النى تقام في مصر لتتجيع وتحفيز السائحين من مختلف دول العالم لمشاهدتها. ثُالثا : فيما يخص الامكانات المادية والبشرية في مجال السياحة الرياضية: -

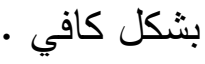


- - نقص البرامج التدربيية للعاملين بالقطاع السياحى وقلة العمالة المدربة والمؤهلة فى بعض المنشآت التى تخدم النشاط الرياضى بمختلف الأماكن السياحية - قلة تتوافر الكوادر المؤهلة لتنظيم المسابقات الرياضية للسائحين - الأدوات والأجهزة الرياضية المنوفرة تحقق أهداف السياحة الرياضية. - المنشآت الرياضية الحالية صالحة لخدمة السياحة الرياضية المتميزة . رابعاً : فيما يخص التحديات المعاصرة التى تؤيثر على السياحة الرياضية محلياً وعالمياً

- تعدد التكتلات الإقتصادية وتعظم تأثيرها على مصر -

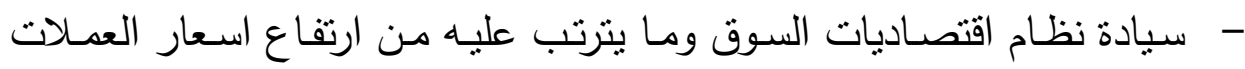
الاجنبية وانخفاض سعر العملة المحلية داخل مصر • - المشكلات السياسية الخاصة بمصر وما ينتج عنها من أعمال العنف والارهاب

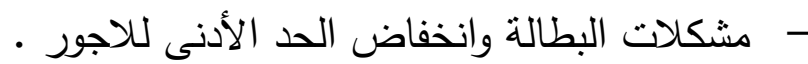

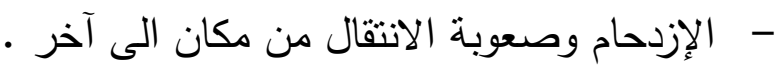
- الزيادة السكانية ـ - موضعف البنية التحتية اللازمة لخدمة السياحة الرياضية. استخلاصاث البحث : أولاً : أن أهم امكانات السياحة الرياضية بمدينة سفاجا تتمركز في الآتي

1. وجود نقاط الغطس المليئة بالشعاب المرجانية والأسماك العديدة المختلفة .

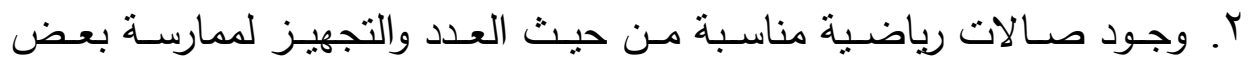
الأنشطة الرياضية المرغوبة للسائح. r. وجود الساحل علي امتداد المدينة بما يسمح اقامة العديد من الأنشطة الرياضية والثاطئية المختلفة . ع. توافر الأدوات والملاعب الرياضية. 
•. تتمتع المدينة بالعديد من الكتل الجبلية التي يمكن استخدامها في رياضـة تسلق

$$
\text { الجبال. }
$$

ثانياً: أن أهم امكانات السياحة العلاجية بمدينة سفاجا تتمركز في الآتي :

ا (. تميز مدينة سفاجا بسطوع شمسها.

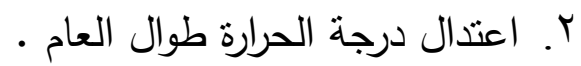

r. تميز مدينة سفاجا برياح معتدلة.

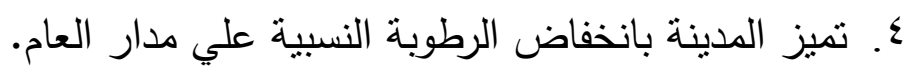

○. ندرة الأمطار.

7. ارتفاع نسبة ملوحة المياه الي اكثر من هب \% والتي تبلغ هـ جزء فالمليون

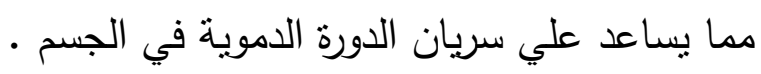

V. شكل الساحل في سفاجا خليجي يؤدى الى هدوء المياه مما يجعلها تعمل كمرآ

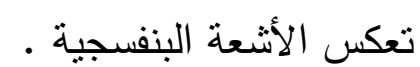

^. وجود اليورانيوم والثوريوم والبوتاسيوم داخل الرمال بالإضافة الي احتوائها علي اغلب عناصـر الفلزيـة كذلك ارتفاع امـلاح الذهب التي تسـاعد علي عـلاج

$$
\text { امراض الروماتويد والروماتيزم . }
$$

ثالثاً: من أبرز المناشط السياحية الرياضية التي نفذت فعلياً بمدينة سفاجا ما يلي:

ا ـ أنشطة الغوص واكتشاف البحر الأحمر.

r. أنشطة صيد الاسماك.

r. مارسة هواية الغطس

ع. ممارسة انشطة الكايك (الابحار بالقوارب).

رابعاً: من أبرز المناشط السياحية العلاجية التي نفذت فعلياً بمدينة سفاجا ما بلي: 
ا ـ ـ برامج العلاج الطبيعي للرشاقة والجمال والنحافة. r ا برامج العلاج الطبيعي، علاج الروماتيزم والروماتويد.

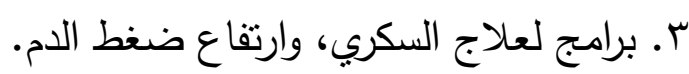

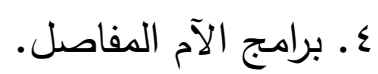
ه. أنشطة المساج بالزيوت الطبيعية.

خامساً: أن من أبرز المناشط السياحية الرياضية التي بمكن تفعيلها

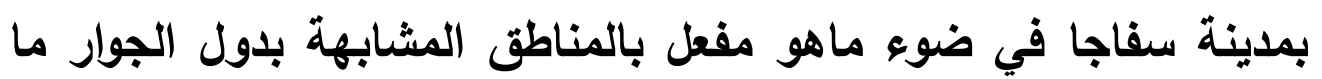

$$
\begin{aligned}
& \text { يلي : } \\
& \text { 1 - مناشط المساج. } \\
& \text { r- مناشط حمامات البخار - } \\
& \text { r- مناشط التخسيس. } \\
& \text { عـ الاستمتاع والاسترخاء بالمياه. } \\
& \text { هـ علاج التهابات المفاصل. } \\
& \text { ד- علاج امراض الروماتيزم • }
\end{aligned}
$$

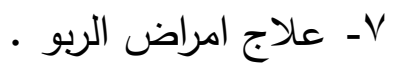

$$
\begin{aligned}
& \text { ^- علاج امراض الكبد والمعدة. } \\
& 9 \text { - علاج امراض النساء . }
\end{aligned}
$$

سادساً: أن من أبرز المناشط السياحية العلاجية التي يمكن تفعيلها بمدينة سفاجا في ضوء ماهو مفعل بالمناطق المشابهة بدول الجوار ما

$$
\begin{aligned}
& \text { يلي : } \\
& \text { 1 ـ اليخوت. } \\
& \text { r. السباحة } \\
& \text { r. الجولف }
\end{aligned}
$$




$$
\begin{aligned}
& \text { ء. ركوب الخيل } \\
& \text { هـ البولينج } \\
& \text { 7. سباق السيارات } \\
& \text { V. تسلق الجبال } \\
& \text { ^. كرة القدم } \\
& 9 \text { ـ الغوص } \\
& \text { • إ. التزحلق علي الماء } \\
& \text { Iا ـ الرماية }
\end{aligned}
$$

النموذج المقترح لتفعيل امكانات السياحة الرياضية والعلاجية بمدينة سفاجا بمحافظة البحر الأحمر

$$
\text { اولاً : أهداف النموذج المقترح }
$$$$
\text { يسعي النموذج المقترح إلي تحقيق الاتي: }
$$

1- الارتقاء بمستوي الخدمات السياحية المتوافرة.

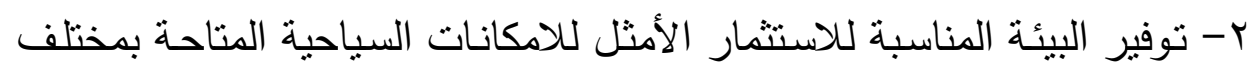

أنواعها (طبيعية - مادية - بشرية ) والاهتمام بالسياحة الداخلية والخارجية.

ب- توافر عوامل الأمن والسلامة عند ممارسة الأنشطة الرياضية والعلاجية.

ع - وضع أنشطة تتماشي مع الثباب والسيدات وكبار السن والأطفال.

0- نشر الوعي الترويحي العلاجي في البحر الاحمر خاصـة وجمهوريـة مصر

$$
\text { العربية عامة. }
$$

○ـ تطوير أداء التسويق والاعلام لجذب السياحة الرياضية والعلاجية.

ثانياً : الهيكل التنظيمي للنموذج المقترح لتفعيل امكانات السياحة الرياضية العلاجية بمدينة سفاجا بمحافظة البحر الأحمر 


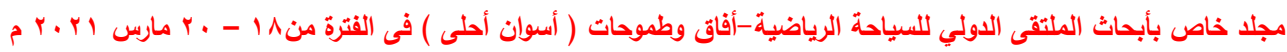
(العدد الثالث) مارمن

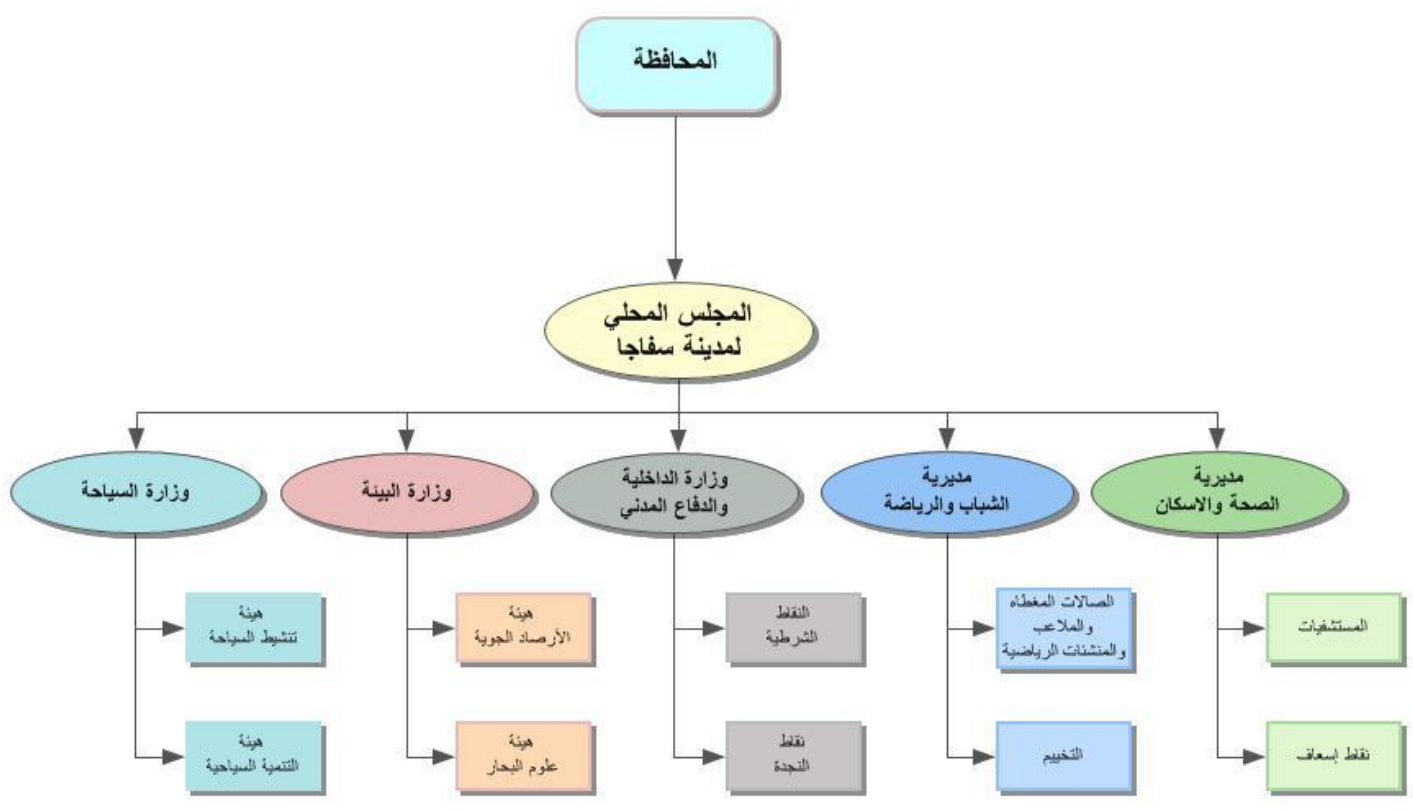




\section{ثالثاً : المهام والمسؤوليات لأعضاء الهيكل التظيمي المقترح المهام والمسؤوليات لأعضاء مديرية الصحة والسكان :} 1- اطباء متخصصون: اطباء متخصصون في الحالات المختلفة التي قد تصيب السائحين في مجال الأمراض الجلدية والرئوية وطب الأعماق.

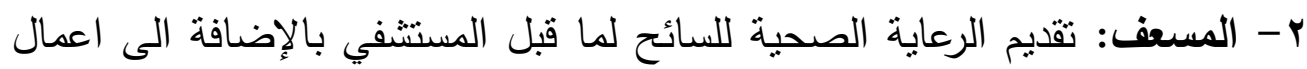
الاغاثة والإبلاغ عن الحالات المريضة ومراقبنها والنقل بها الي اقرب مركز طبي بالي لهابه وتوجيه النصح والارشاد للسائح المريض للحد من المخاطر الصحية التي قد تلم به. r- أخصائيون في مجال السياحة العلاجية: تقييم المريض وتحديد مشكلته ومن ثم تعيين الطرق المناسبة لحلها وذللك من خلال جلسات علاجية يتم تحديدها بناءً على حالة المربض

المهام والمسؤوليات لأعضاء مديرية الشباب والرياضة : - منقذون: مراقبة الثواطئ وتوجيه النصح والارشاد للسائح وعمل الإسعافات الأولية لحين حضور المسعفون. r - أخصائيون رياضيون: القيام بكل نشاط رياضي ترويحي داخل المنتجع السياحي ، وتتظيم المسابقات الترفيهية داخل المنتجع السياحي. r- دليل كشفي: توجيه الأفراد اثناء الرحلة الخلوية والتعرف علي كل فرد في الرحلة وظروفهم الصحية وتهيئة أماكن الرحلة . المهام والمسؤوليات لأعضاء وزارة الداخلية والدفاع المدني: 1- أفراد خلمات الحراسة والأمن: حماية المنتجعات السياحية من اخطار السرقة او الحريق وتامين البوابات والاسوار وكل مايخص المنتجع ومابداخله من افراد واثاث ومعدات r - أفراد النجدة : القيام بكل نشاط يتعلق باستغاثة ومعاونة أفراد الأمن من حرائق وخلافه 


\section{المهام والمسؤوليات لأعضاء وزارة البيئة :}

1- خبراء في علوم البحار: نحديد أكثر الأماكن ملائمة لإقامة الأنشطة التي لا تؤثر علي البيئة

r- خبراء في الأرصاد الجوية : تحديد أكثر الأوقات ملائمة لإقامة الأنشطة وخاصة الأنشطة الطويلة المدي حتي يستمتع السائح بأكبر وقت ممكن الأن المهام والمسؤوليات لأعضاء وزارة السياحة :

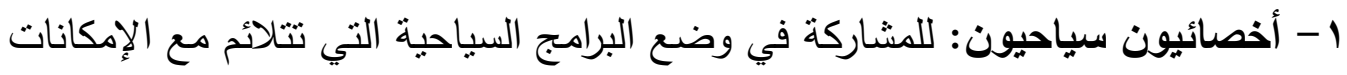
المتاحة

ץ- مترجمون: لمعاونة السائحين علي استبعاب الأنشطة السياحية المختلفة وتتفيذها رابعاً: المؤهلات والمهارات المطلوية لأعضاء الهيكل التنظيمي المقترح 1- اطباء متخصصون : خريج كلية طب

r- المسعفون: حاصل علي شهادات من مركز الهلال الأحمر في الاسعافات الأولية ورخصة في مجال الاسعاف بمزاولة المهنة r- منقذون: حاصل علي شهادات من الاتحاد المصري للغوص والإنقاذ بمزاولة المهنة ع - أخصائيون رياضيون: خريج كلية التربية الرياضية

ه- دليل كثفي: حاصل علي شهادات من الاتحاد الدصري للكثافة بمزاولة المهنة צ- أخصائيون في مجال السياحة العلاجية: خريج كلية العلاج الطبيعي - كلية الطب (قسم أمراض الجلدية) - أخصائيون في مجال السياحة: خريج كلية السياحة والفنادق 1- مترجمون : حاصل علي كلية لغات وترجمة فورية أو معاهد السياحة او دورات لغات مختلفة مع شرط الكفاءة والطلافة. 9- خبراء في علوم البحار : خريج كلية علوم البحار او معاهد علوم البحاء البحار

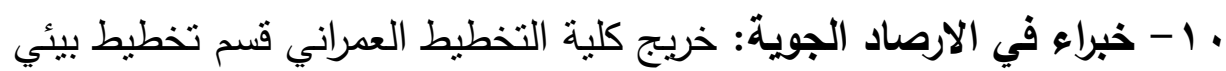


1 - افراد الخدمات والحراسة والأمن :خريجي كليات الثرطة والهيئات التابعة لوزارة

الداخلية

الأنشطة المقترحة للسياحة الرياضية في ضوء نتائج البحث :

ا ـ أنشطة الغوص واكتشاف البحر الأحمر.

r. (أنشطة صيد الاسماك.

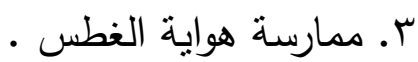

ـ ـ ممارسة انشطة الكايك (الابحار بالقوارب) •

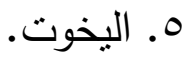

7. السباحة

V. الجولف

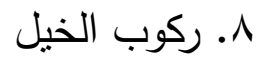

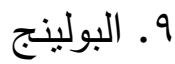

• ا ـ سباق السيارات

1ا ـ نسلق الجبال

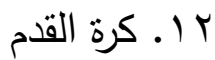

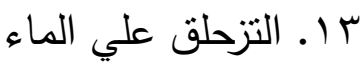

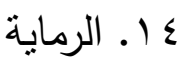

الأنشطة المقترحة للسياحة العلاجية في ضوء نتائج البحث :

1. مناشط العلاج الطبيعي للرشاقة والجمال والنحافة.

r. مناشط علاج الروماتويد.

؟. مناشط لعلاج السكري، وارتفاع ضغط الدم.

ع. عناشط الآم المفاصل.

هـ أنشطة المساج بالزيوت الطبيعية.

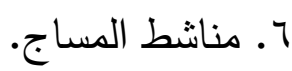




$$
\begin{aligned}
& \text { V. مناشط حمامات البخار . } \\
& \text { ^. مناشط التخسيس. } \\
& 9 \text { 9. الاستمتاع والاسترخاء بالمياه. } \\
& \text { • 1 - علاج التهابات المفاصل. } \\
& \text { 1) } \\
& \text { r ا - علاج امراض الربو . } \\
& \text { זا ا - علاج امراض الكبد والمعدة. }
\end{aligned}
$$

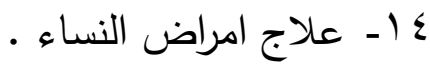

\section{التوصيات}

في ضوء الإجراءات التي تمت في هذه الدراسة وفي حدود عينة البحث المختارة

واستنادا إلي النتائج والاستتناجات السابقة يمكن التوصية بالآتي:-

ا - اعتماد النموذج المقترح لتفعيل امكانات السياحة الرياضية والعلاجية بمدينة

سفاجا من الجهات المختصة . المعت

r- التقدم بالنموذج المقترح الى المؤسسات والهيئات التنفيذية الخاصة بتتشيط

السياحة بمصر عامة و بمدينة سفاجا على وجه التحديد .

r- طبع نشرات ارشادية وتوجيهية خاصة بتوعية المواطنين بمدينة سفاجا بالجوانب

المكملة لتفعيل وتتشيط السياحة بالمدينة .

عـ - اجراء دراسات لاحقة تهتم باستراتيجيات تطوير مناشط السياحة الرياضية

والعلاجية بمدينة سفاجا بالبحر الأحمر . 


\section{قائمة المراجع}

\section{أولا: المراجع باللغة العربية}

I. أبوبكر عوني عطية : النتظيم الدولي للسياحة الرياضية (نحو إنشـاء منظمـة دوليـة مقترحة للسياحة الرياضية) ،الطبعـة الأولىى، دار الوفاء للدنيا الطباعـة

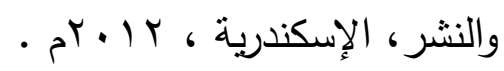

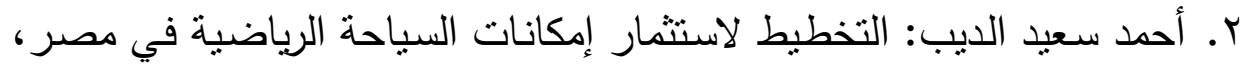
رسالة ماجستير، كلية التربية الرياضية، جامعة طنطا، جمهورية مصر العربية،

$$
\cdot 0 r \cdot 1 \mathrm{~V}
$$

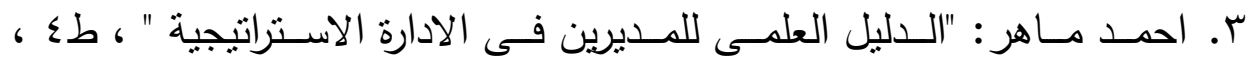

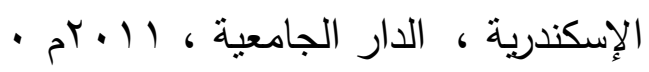

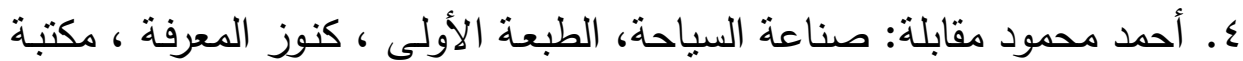

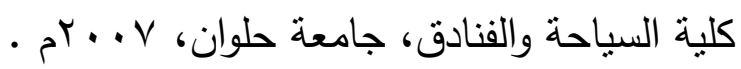

๑. أحمد نبيل كامل الثيخ : دور السياحة ال رياضية فى تتمية الموارد بالإتحادات الرياضية بجمهورية مصر العربية، رسالة ماجستير غير منشورة ، كلية التربية

$$
\text { الرياضية للبنين، جامعة الزقازيق ، ع . . بـم • }
$$

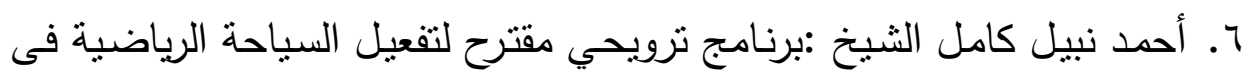
ج·م•ع ، رسالة دكتوراه غير منشورة، كلية التربية الرياضية ، جامعة الزقازيق لبريق

$$
\text { - } \hat{N} ו r
$$

V. أشرف سمير الميداني: السياحة الرياضية في مصر، دار الوفاء لدنيا الطباعة

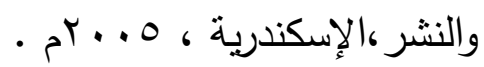

^. أنبس فتحى،الإمـارات إلى أبن ..استشـراف التحديات والمخـاطرعلى مدىه

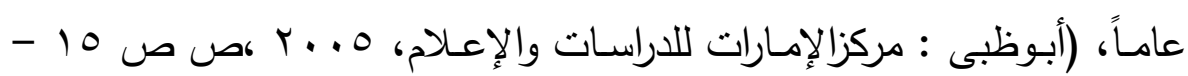


9. الدولة المضيفة، رسالة ماجستير غير منشورة ، كلية التربية الرياضية للبنات،

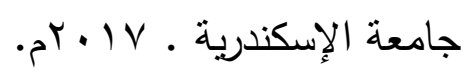

• ا.ريــ صــلاح المقـانى: إسـتراتيجية ترويجيـة للسـياحة الرياضـية بمحافظــة

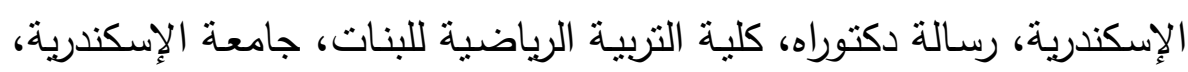

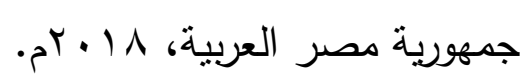

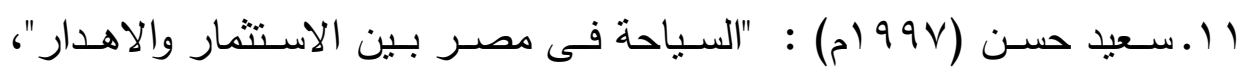

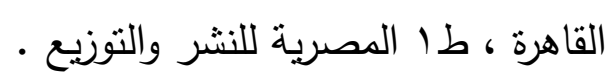

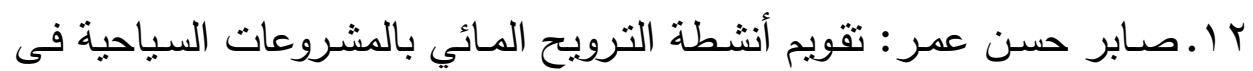

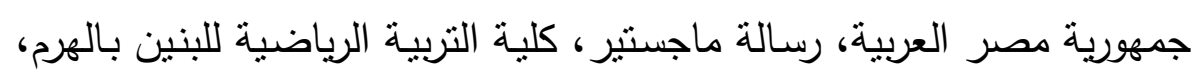

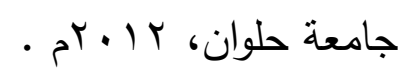

با. عـادل طـاهر (999 (م) : " الرياضــة والسـياحة" المجلس الـولي للتربيـة الرياضية والبدنية، السكرتارية الإقليمية للافريقيا والثرق الأوسط ، القاهرة

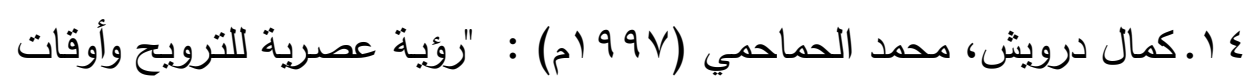
الفراغ "، طا - مركز الكتاب للنشر ، القاهرة ؟ دمبن

1 ـ مـدحت قاسـ، أحمد عبد الفتـاح :السـياحة الرياضـية والمنتجعـات الصـحية

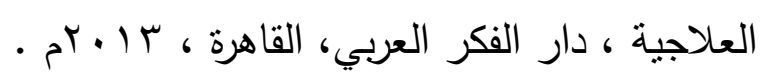

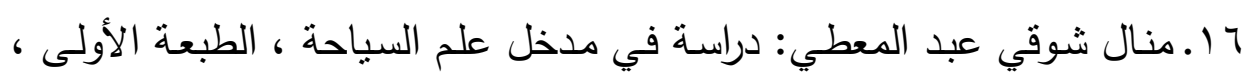

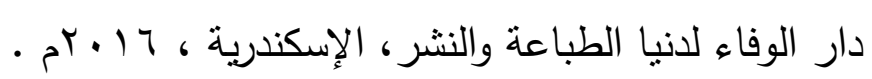

V ا نادية لطفي عبدالفتاح معوض :نتظيم الدورات الأولمبية وانعكاساتها إقتصادياً

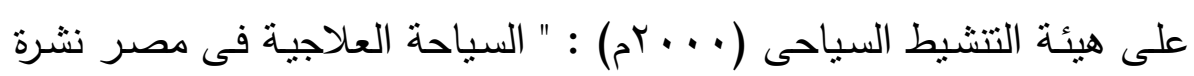
المعلومات السياحية" ، الإدارة العامة للمعلومات ،وزارة السياحة. الهئه

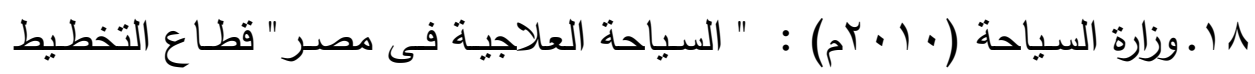
والبحوث والتدريب، القاهرة . 
9 1 ـ ياسبن الكحلي: دور السياحة في التتميـة الاقتصـادية والإجتماعيـة والنقافيـة،

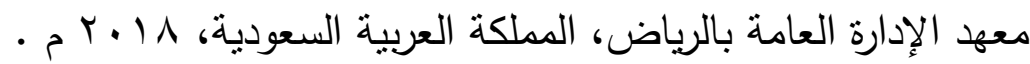

\section{ثانيا: المراجع باللغة الاجنبية}

20.Amira Hassan Abdou Mohamed ( 2010 ): The role of the sport events in developing the imported tourism to egypt, master degree, Fuclty of tourism and hotel management, Tourism studies department, helwan university. Cairo.

21.Barnes: Sports, Tourism, and Economic Development, Cleveland State University, July, 12-14, 2005.

22.Dawid .J. delivers: Sport and Tourism to Stimulate Development world conference on sports and tourism, Barcelona, SPAIN feb, 2012.

23. Freyer,W: Sport und Tourismus, Megamarkte In Der Wissen Schaftlchen Disk ussion In Troslen, G, 2010.

24. Heather J. Gibson: Sport Tourism, Published by: Rout ledge, $24^{\text {th }}$ December 2017.

25.Kreilkamp, E, (2002) : Ausullr kungen freizeit sportlicher Emtwic klungen auf den tourismus mit aktudlen Daten ausdem golf sport in, Dreyer, A, (Hrsg) tourismus und sport wesbaden 